\title{
THE IMPACT OF ACTIVE LIFESTYLE ON FUNCTIONAL FITNESS LEVEL OF OLDER WOMEN
}

\author{
A Thesis by \\ Samuel Ofei-Dodoo \\ Master of Public Administration, Wichita State University, 2010 \\ Submitted to the Department of Public Health Sciences \\ and the faculty of the Graduate School of \\ Wichita State University \\ in partial fulfillment of \\ the requirements for the degree of \\ Master of Arts
}

July 2012 
(C) Copyright 2012 by Samuel Ofei-Dodoo

All Rights Reserved 


\section{THE IMPACT OF ACTIVE LIFESTYLE ON FUNCTIONAL FITNESS LEVEL OF OLDER WOMEN}

The following faculty members have examined the final copy of this thesis form and content, and recommend that it be accepted in partial fulfillment of the requirement for the degree of Master of Arts with a major in Aging Studies.

Nicole L. Rogers, Committee Chair

Suzanne Hawley, Committee Member

Michael E. Rogers, Committee Member 


\section{DEDICATION}

To my mother, Elizabeth Ampofo for her sacrifices over the years. 


\section{ACKNOWLEDGEMENTS}

I owe a debt of gratitude to many people who have directly and indirectly contributed to this project. I would like to express my sincere appreciation to Dr. Nicole L. Rogers for her immense support and guidance during the entire time of the project. I wish to acknowledge Dr, Amy Morgan, Sahar Amini, and Jenifer Gurnsey whose work has provided an example that have been used in this paper. I also thank the committee members for their constructive criticisms, and finally, I would like to thank Dr. Ed Flentje, Dr. Nancy McCarthy-Snyder, Dr. Melissa Walker, Aanaiyah Saechao, Rachel Owens, and Joshua Allotey Snr. for their encouragement and support. I am ever grateful to all. 


\begin{abstract}
As adults reach advanced ages, the purpose of physical activity may shift from disease prevention to functional fitness and mobility. The purpose of the study is to test the hypothesis that engaging in an active lifestyle is associated with higher functional fitness in older women. Functional fitness was assessed by the Senior Fitness Test in 125 women (73.42 \pm 8.84 yrs). Participants wore an accelerometer for 7 days without altering their normal activity. Accelerometer data were downloaded, moderate and vigorous physical activity (MVPA) determined via proprietary filtering, and time spent in each intensity was calculated. A 5 day average of time spent in MVPA was organized into 4 groups. Frequency distributions were calculated to examine the number of participants meeting ACSM recommendation for MVPA. With respect to MVPA, only $18 \%$ of participants met ACSM recommendations by engaging in 30 minutes of moderate intensity physical activity for at least 5 days per week. Nearly half of the participants were classified as normal on most functional measures.

To determine if a relationship existed between the participants 5 day MVPA, functional fitness, age and weight, correlation coefficients were calculated. The strongest relationships were found between MVPA and the 6 min walk $(r=0.52, p \leq 0.001)$, chair stands $(r=0.46, p \leq$ $0.001)$, and up \& go $(\mathrm{r}=-0.44, p \leq 0.001)$. To determine if engaging in an active lifestyle is associated with higher functional fitness, participants were grouped by time spent in moderate intensity physical activity to determine a cut-off on improvement observed in functional fitness. MVPA group comparisons were made using one-way ANOVAs with follow-up Post Hoc analysis. The results revealed significant differences between groups on all measures except sit and reach. The one-way ANOVA indicated a threshold of 20 minutes for the 6 min walk, chair stand, and up \& go. With regard to upper body strength and flexibility, less than 10 min of MVPA was observed to be detrimental to performance.
\end{abstract}


1. INTRODUCTION

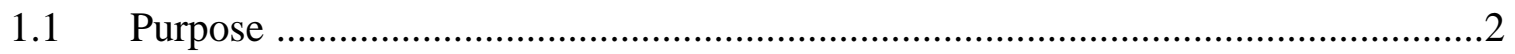

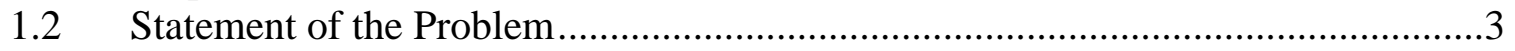

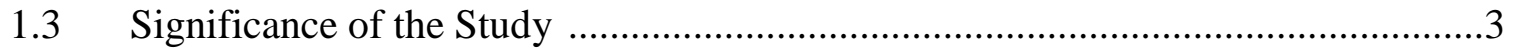

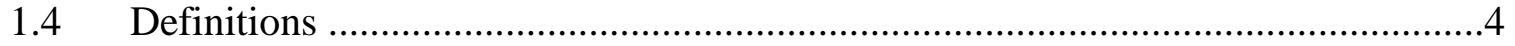

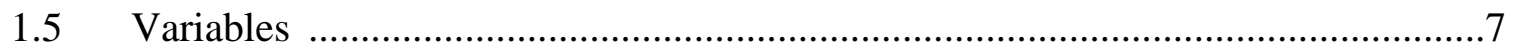

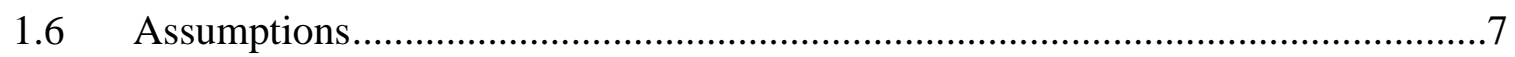

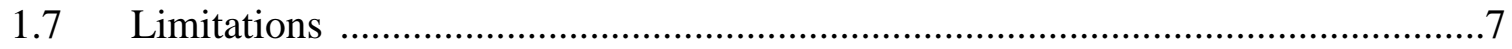

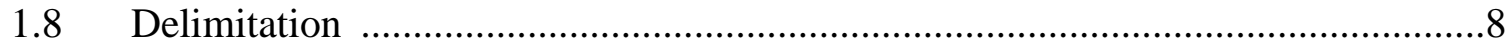

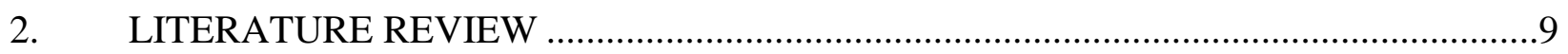

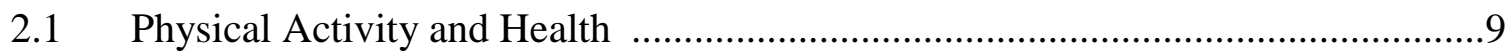

2.2 Physical Activity and Functional Fitness ……..................................................15

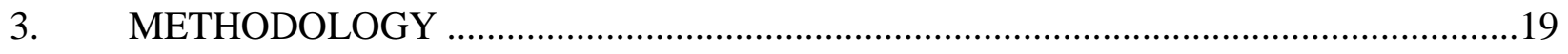

3.1 Study Population and Screening ………………..........................................19

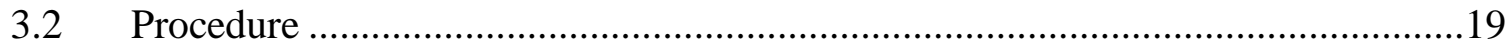

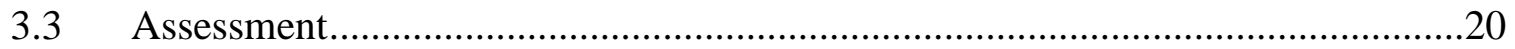

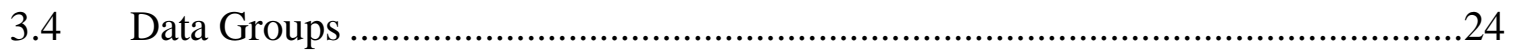

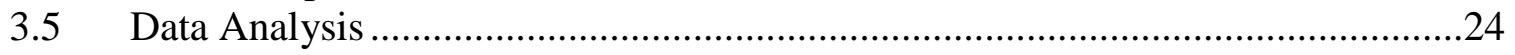

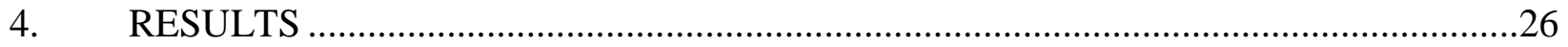

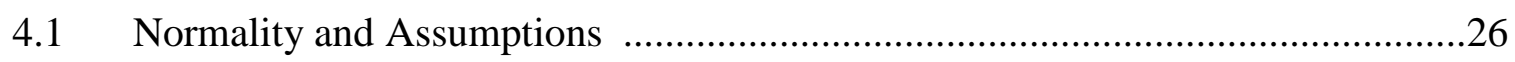

4.2 Participants Characteristics ............................................................................26

4.3 Relationship between MVPA and Functional Fitness .........................................29

4.4 Moderate Intensity Cut-Off Points..........................................................................31

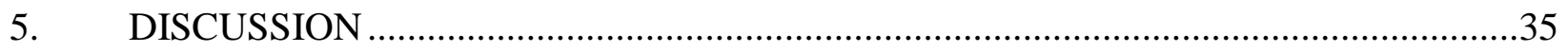

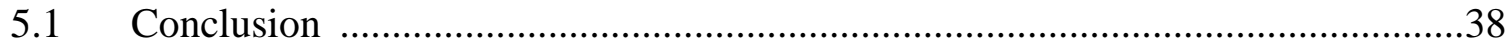

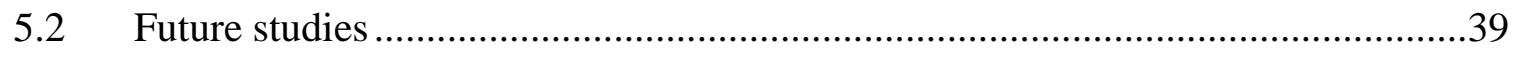

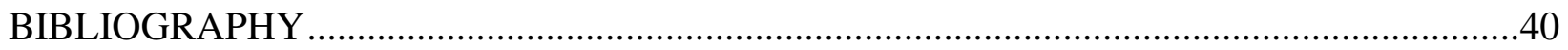




\section{TABLE OF CONTENTS (Continued)}

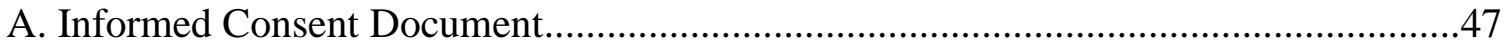

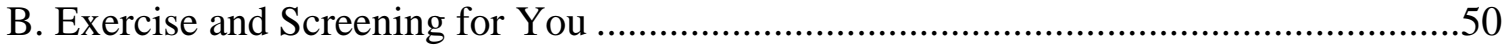

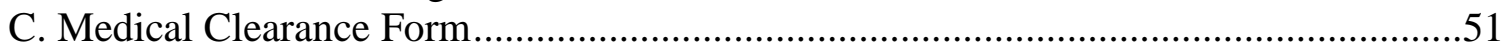

D. Demographic Questionnaire Document...............................................................53 


\section{LIST OF TABLES}

Table

Page

3.1 5 day average of time spent in moderate intensity physical activity by group ................24

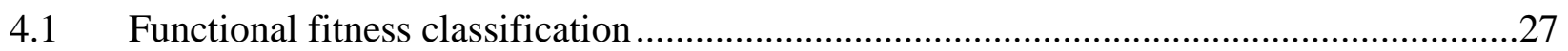

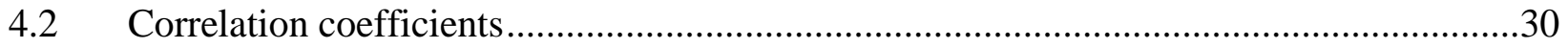

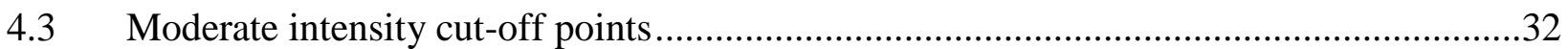




\section{LIST OF FIGURES}

Figure

Page

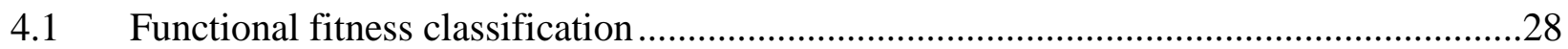

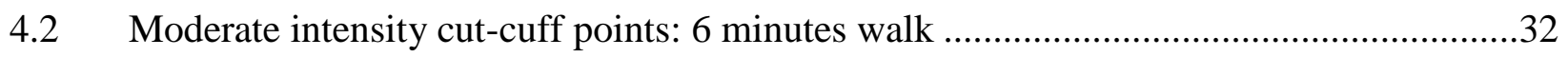

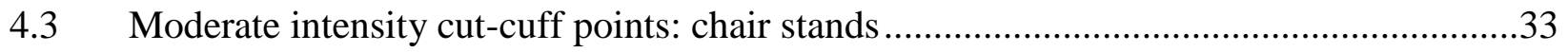

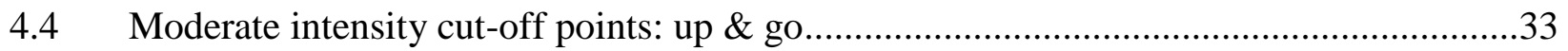

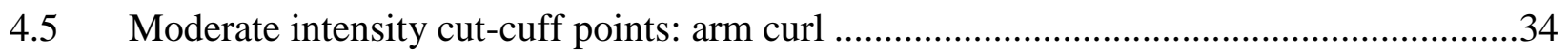

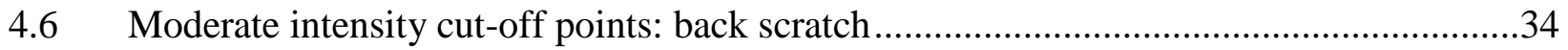




\section{CHAPTER 1 \\ INTRODUCTION}

The older population is growing very fast and the United Nations (2003) have estimated that the number of older people aged 60 and older throughout the world would reach over 1.9 billion by 2050. This observation is not different in the United States. The older population has been found to be the fastest growing age group in the United States, yet the least active group (HHS, 2008). The American College of Sports Medicine (ACSM) recommends that regular, moderate intensity physical activity is key to good health (Nelson, Rejeski, Blair, Duncan, Judge, King, et al., 2007). The Centers for Disease Control and Prevention (CDC) and the American Heart Association agree with ACSM's recommendations that to maintain good health adults should spend a minimum of 30 minutes, 5 days/week doing moderate intensity physical activity or 20 minutes engaging in vigorous-intensity activity for at least 3 days/week.

Other studies have also shown that physical condition (balance, walking speed and lowerextremity strength) is important to the health and functional fitness in old age (Yamauchi, Islam, Koizumi, Rogers, Rogers, \& Takeshima, 2005; Rogers, Sherwood, Rogers, and Bohlken, 2002; Morgan, Tabor, and Snyder, 2010). Functional fitness predicts the likelihood of older adults developing disease, disability, hospitalization, and mortality (Aoyagi, Park, Watanabe, Park, \& Shephard, 2009). Maintaining this function also helps older adults stay independently in their home (Rikli and Jones 1999a).

Physical unhealthiness can lead to further health complications such as cancer, obesity, cardiovascular disease, and ultimately decreased longevity (Woolf, Reese, Mason, Beaird, Tudor-Locke, \& Vaughan 2009). Moreover, Aoyagi \& Roy (2009) have documented that there 
is a positive association existing between habitual daily physical activity and functional fitness. The 2008 Physical Activity Guidelines Advisory Committee Report states that, in addition to health benefits associated with regular physical activity for older adults, there is a strong relationship between physical activity and higher levels of functional fitness, lower risk of falling, and even better cognitive ability. In spite of the benefits of maintaining an active lifestyle, many older adults are inactive. The CDC reports that in 2005, only $49.1 \%$ of U.S adults met the ACSM/CDC physical activity recommendation (Haskell, Lee, Pate, Powell, Blair, et al. (2007). With this, the report shows that $50.7 \%$ men as compared to $47.9 \%$ women met their recommendation; indicating that men are more likely to meet the ACSM/CDC physical activity recommendation.

Data from 2005 showed that compared to older people, younger people are more likely to be active. The prevalence of those meeting the recommendation declined by $20.6 \%$ (59.6\% among 18-24 year olds and 39.0\% among people in 65 years and older). The Department of Health and Human Services (2005) reports that only $25 \%$ of women $65-74$ years participate in regular physical activities and only $14 \%$ of women 75 years and older engage in any physical activity; engaging in "no leisure time, household, or transportation physical activity" (CDC, 2001).

\subsection{Purpose}

Therefore, the purpose of the current study was to test the hypothesis that engaging in an active lifestyle (amount and intensity) is associated with higher functional fitness in older women. Frequency distributions were calculated to examine the number of participants meeting ACSM recommendation for moderate and vigorous physical activity (MVPA) as well as the 
number of participants with normal functional fitness as determined by the Rikli and Jones classification. The relationship between time spent in moderate intensity physical activity and functional fitness was examined. Participants were also grouped by their time spent in moderate intensity physical activity to determine a cut-off on improvement observed in functional fitness.

\subsection{Statement of the Problem}

As adults advance in age, "their chronic disease is well established" and the purpose of physical activity may center more on their functional fitness (a concept reflecting an older adult's ability to perform the physical activities of daily life with relative ease - requires strength, balance, cardio, and flexibility). Active lifestyle is critical in delaying the onset of functional limitations, maintaining independence, and improving quality of life. The findings of the study will be an evidence-based guideline that will advance the strength of other studies that purport the importance of older women engaging in active lifestyle to stay functional active and independent.

\subsection{Significance of the Study}

It has been established that engaging in regular moderate intensity physical activity helps maintain and promote health (Nelson, et al., 2007). Engaging in this type of activity also helps older adults improve and/or maintain their physical fitness and functional independence, but not all older adults engage in the recommended 30 minutes of moderate or 20 minutes of vigorous exercise. The ability for older adults to live independently in their own home is to a large extent dependent on their functional fitness, which is a reflection of their ability to perform their everyday activity with ease. For older adults to perform their everyday activity (personal care, 
housework, shopping), according to Rikli and Jones (1999a), is dependent on their capabilities to engage in functional movements such as walking, stair climbing, standing, etc., which in turn depends on having enough energy to perform those tasks without undue fatigue. So the study will help older adults to understand that if they are not able to meet the recommended exercise regimen, they could engage in physical activities that may be less than what is recommended and still be functionally active. Generally, this study will improve the knowledge concerning the potential of active lifestyle to improve the functional fitness of older individuals, thus, enhancing the ability to help older adults to live independently in their homes and community for longer periods of time. In addition, the study will contribute to our understanding of the relationships between active lifestyle and functional fitness in older adults.

\subsection{Definitions}

1. Active lifestyle: Lifestyle activities that positively contribute to the improvement of physical, mental, and social well-being of people. This includes regular exercise and physical activities. According to Haskell et al. (2007), life activities like brisk walking, gardening with the shovel, carpentry conducted in bouts of 10 minutes have been found to be part of physical activity recommendations presented by ACSM/CDC. To maintain an active lifestyle, it is important that people engage in physical activity and the simplest and least expensive form is walking. For those who do not enjoy walking could engage in other activities like swimming, dancing, or bicycling. Since walking has been found to be the most prevalent and preferred physical activity mode (Williams, Matthews, Rutt, et al., 2008), and the easiest way to measure active lifestyle, walking will be used to assess the active lifestyle of the study participants. Behavioral Risk Factor Surveillance by 
Simpson, Serdula, Galuska, et al. (2003) estimates that between 1987 and 2000, about $30 \%$ of U. S men and $47 \%$ of U.S women reported walking in their leisure time with over half of U.S adults reported engaging in walking 3 days/week for at least 30 minutes.

2. Physical Activity: Physical Activities: Any body movement that is produced by the skeletal muscles, requires energy, and results in energy expenditure (Caspersen, Powell, and Christenson, 1985). Walking, dancing, swimming, running, gardening, yoga, etc. have all been cited by the U. S. Department of Human Services as some of the examples of physical activity. The 2008 Physical Activity Guidelines for Americans, the HHS refers physical activity as any "movement that enhances health."

3. Exercise: Exercise: Exercise is often used in synonymous with physical activity because they require skeletal muscle movements and energy expenditure. However, exercise has been reported to be a sub-category of physical activity that is structured, planned, and requires repetition with the aim of either improving or maintaining physical fitness (Caspersen, Powell, and Christenson, 1985). Weight lifting, power skipping, rocket jump, lateral bound, pushups, etc. are examples of exercise. Occupational and household tasks/activities that are planned and structured with consecutive energy expenditure and little or no regard to physical fitness are documented not to be exercise. However, those activities that are performed in a labor producing manner, aim at producing muscle strength, and "burn up" calories are considered exercise (Caspersen, Powell, and Christenson, 1985).

4. ACSM Recommendations: In an attempt to provide a clear public health message and to encourage healthy U.S adults between 18 and 65 years to maintain and promote health, the ACSM/CDC issued a public health recommendation that these adults need to 
accumulate at least 30 min moderate-intensity aerobic physical activity 5 days/week or vigorous-intensity aerobic physical activity for $20 \mathrm{~min} 3$ days/week (Haskell et al., 2007). Combination of both the moderate-intensity aerobic activities and vigorous-intensity could be used to achieve the recommendation. According to Haskell et al. (2007), to achieve the recommendation, a person can engage in 30 min brisk walking for two days and 20 min jogging for two days. The 30 min brisk walking could be achieved in a bout lasting for 10 min or more.

5. Moderate Intensity Physical Activity: Generally equivalent to brisk walking, dancing, gardening, housework and domestic chores, etc. that require moderate amount of effort and "noticeably accelerate the heart rate" (Haskell, 2007). This is also calculated as 50\%-70\% of maximum heart rate.

6. Accelerometer: Kenz Lifecorder accelerometers (ACCEL) (Suzuken Company, Nagoya, Japan) were used to assess the active lifestyle levels of the participants. The ACCEL records physical activity intensities in ten different levels - zero to nine, with higher numbers indicating higher intensity. The intensity levels are determined via a proprietary filtering process that considers frequency and magnitude of accelerations. Previously developed and validated formulas were used to calculate time spent in each intensity: $0=$ non-ambulatory, $1-3=$ light, $4-6=$ moderate and 7-9 = vigorous. The ACCEL is uniaxial, small in size (62.5 mm $\square 46.5 \mathrm{~mm} \square 26.0 \mathrm{~mm})$, light in weight ( $40 \mathrm{~g}$ ), and powered by a lithium battery (CR2032, 3V). According to the device, acceleration is sampled every four seconds and recorded at two minute intervals (Crouter, et al., 2003). The daily activity summary files of each participant were downloaded to an Excel spreadsheet to determine physical activity intensities. Time spent in each intensity 
(sedentary, low, moderate, vigorous) was calculated. A 5 day average of time spent in MVPA was organized into 4 groups.

7. Functional Fitness: Functional fitness is a concept that reflects an older adult's ability to perform physical activities of daily life with relative ease (Rikli and Jones, 1990a). This concept accounts for traditional physical fitness parameters such as muscle strength, cardio-respiratory endurance, and flexibility, and also includes balance. Even in healthy adults, each component of functional fitness declines with advancing age, negatively affecting quality of life (Donato, Tench, Glueck, Seals, Eskurza, et al. (2003).

\subsection{Variables}

This project was a quasi-experimental study aimed at determining the effect of active lifestyle on the functional fitness levels of older women. Depending on the grouping being evaluated, accelerometer data and functional fitness will serve as an independent and dependent variable.

\subsection{Assumptions}

It was assumed that the participants would wear the accelerometer during all waking hours of the research period.

\subsection{Limitations}

The results of the study could have been affected by the following limitations: The accelerometers do not provide objective measure of all forms of active lifestyle; thus, are not capable of recording some lifestyle activities like swimming, bicycling, weight-training, yoga, 
gardening with shovel, dancing (Tudor-Locke, Hart, \& Washington, 2009; Haskell, Lee, Pate, Powell, Blair, et al. (2007), and this could affect the accuracy of participant's total daily activities. Secondly, environmental factors (such as humidity, precipitation, and day length, duration of bright sunshine and the mean ambient temperature) could affect results. For example, the time spent in engaging in physical activity/active lifestyle is likely to decrease with increasing precipitation.

\subsection{Delimitations}

The results of the study apply to older women, aged 55 to 95 years living in urban cities. 


\section{CHAPTER 2}

\section{LITERATURE REVIEW}

\subsection{Physical Activity and Health}

Physical activity is associated with positive physical and mental health (Buchman, Boyle, Yu, Shah, Wilson, et al., 2012; Yaffe, Nevitt, Lui, and Covinsky, 2001). A vast amount of research supports the hypothesis that regular physical activity improves health and function, and contributes to the prevention or delay of disability and disease. Despite this evidence, most Americans are not sufficiently physically active (CDC, 2003). "Getting people to adopt and then maintain a regular physical activity program are two of the biggest challenges facing public heath in developed nations, including the United States" (Dishman, Washburn, and Heath, 2004). Unfortunately, more than one-half of US adults do not meet the public health recommendations for physical activity and those over the age of 50 years are least activity (34\%) (CDC, 2003).

The efficacy of exercise for older adults is evidenced in a multitude of epidemiological and clinical studies. Longitudinal studies have confirmed the cross-sectional studies that link exercise to reduced risk of disease and disability. Most notably, researchers have demonstrated a relatively immediate benefit of lifestyle changes, such as exercise, even among elderly and highrisk persons (Fiatarone-Singh, M. A. (2001). According to Fiatarone-Singh (2001), exercise is beneficial for the following diseases and syndromes: arthritis, cancer (breast, colon, prostate), chronic renal failure, congestive heart failure, coronary artery disease, depression, frailty and disability, gout, impotence, insomnia, impairment mobility and falls, osteoporosis and osteoporotic fracture, stroke, type 2 diabetes mellitus, and urinary stress incontinence. Postulated mechanisms of the exercise effect include decreased blood pressure, decreased body weight, 
decreased LDL cholesterol, increased HDL cholesterol, decreased insulin resistance, decreased cortisol levels, decreased depression, decreased anxiety, improved sleep, increased self-esteem, increased body mass, increased muscle mass and strength, increased self-efficacy, maintenance of cartilage integrity, improved body balance and gait stability, and others. After reviewing the multitude of benefits that regular physical activity provides, the American College of Sports Medicine (ACSM, 1998) has recommended that older adults engage in a well-rounded exercise program consisting of aerobic, stretching, strength, and balance exercises.

Franco, de Laet, Peeters, Jonker, Mackenbach, et al. (2005) used data from the Framingham Heart Study to determine the effects of physical activity on the life expectancy with cardiovascular disease among people over 50 years. The authors used 4121 participants for the current study where participants were grouped, based on tertiles of physical activity score, into low $(<30)$, moderate (30-33), and high (>33) physical activity levels. The authors used hazard ratio for 3 transitions (healthy to death, healthy to disease, and disease to death) compared with physical activity to perform life table calculations adjusting for age, sex, smoking, and comorbidity. The results indicated that physical activity (moderate and high) prevents cardiovascular disease as well as expanding life expectancy in both men and women. Compared with men over 50 years who engaged in low physical activity, participants who engaged in high and moderate physical activity lived 3.2 and 1.1 years more without cardiovascular disease, respectively. Those who engaged in high and moderate physical activity lived 3.7 and 1.3 years more than those men 50+ years who engaged in low physical activity, respectively. The results on women were not different. Compared to those who engaged in low physical activity, the women participants who engaged in high and moderate physical activities lived 3.3 and 1.3 
cardiovascular free years, respectively. They lived 3.5 and 1.5 more when they engaged in high and moderate physical activity, respectively.

To determine the effects physical activity has on heart rate variability, Rennie, Hemingway, Kumari, Malik, and Marmot, (2003) conducted a Whitehall II Study using 3,328 participants (994 women and 2,334 men) aged 45 - 68 years, between 1997 and 1999. All the study participants were nonindustrial civil servants working in London, United Kingdom. Each participant filled out questionnaire that was prepared based on validated Minnesota leisure-time activity questionnaire (Taylor, Jacobs Jr., Schucker, et al., 1978) indicating the kind and amount of activity they engaged in as well as the time spent engaging in the activity. The numbers were averaged to calculate the total hours each participant spent engaging in physical activity. The authors used Ainsworth, Haskell, Leon, et al. (1993)'s compendium of activity energy costs to assign metabolic equivalent values, which indicated the intensity of the activity. Heart rate variability of each participant was also measured using the European Society of Cardiology/North American Society of Pacing and Electrophysiology Task Force. After adjusting for smoking, and high alcohol consumption, the findings indicate that, among other things, physical activity (both vigorous and moderate) is associated with higher heart rate variability levels, suggesting the possibility that physical activity reduces the risk of heart diseases.

One article of interest was an elegant study involving 5,925 community-dwelling white women aged 65 and older where Yaffe, Nevitt, Lui, and Covinsky (2001) tried to determine the relationship between physical activity and cognitive impairments. The participants' cognitive performance was measured using a "modified Mini Mental State Examination”, which indicated that most participants did not have cognitive impairment or physical limitations at baseline. Six 
to eight years after the baseline measurement, the participants' physical activity was measured by “self-reported blocks $(1$ block $=160 \mathrm{~m})$ walked per week and by total kilocalories (energy) expended per week in recreation, blocks walked, and stairs climbed" (p. 1703).

The findings of the study indicated an association between physical activity and reduced chance of older adults developing cognitive difficulties/impairments among the participants. Whether it was measured as blocks walked per week or as a total kilocalories expended per week, over the 6- to 8-year follow-up, community-dwelling women who had greater baseline physical activity were less likely to develop cognitive decline. The findings support other studies that have shown that physical activities prevent cognitive decline among older adults (Christensen et. al., 1996 and Emery el. al., 1998).

In a prospective study of 2,257 physically capable men aged 71 to 91 year, Abbott, White, Ross, Masaki, Curb, and Petrovitch (2004) evaluated the relationship between walking and older adults' future risk of developing dementia. Initial walking distance of the participants was assessed from 1991 to 1993, and follow-up of incident of dementia was performed from 1994-1996 and 1997-1999 using neurological assessment. The findings of the study showed that active lifestyle (walking) is associated with a reduced risk of dementia among men in this cohort. This means that encouraging physically capable older adult men to engage in physical activity or active lifestyle could help with their late-life cognitive function. Statistically significant, although not substantial, these study findings also indicated that men who walked long distances have reduced prevalence of diabetes and reduced risk of coronary heart disease. Participants who walked less than 0.25 mile within a day had a 1.8-fold risk of experiencing total dementia than those who walked more than 2 miles a day. The incidence of experiencing total dementia among older men was reduced with an increase in the distance they walked. 
A study by Morgan, Tabor, \& Snyder (2010) was aimed to determine if there are positive health, fitness, and psychological benefits when older individuals engage in an accumulated 10,000 steps/day. In spite of many studies that have shown that individual's general well-being improves when they engage in recommended 30 minutes/day physical activities for most days of the week, many older adults, aged 55 years and older do not participate in physical activities on most days of the week. Other studies have also shown that many chronic health conditions could be "prevented entirely, managed, or improved" (p.307) through physical activities, yet many older adults have been inactive and their inactiveness could be attributed to chronic conditions.

After 15-weeks of intervention, the results indicate that although not all functional fitness improvements were statistically significant, there were improvements and they were both physical and psychological benefits. There was a decrease in the total cholesterol level, and a decrease in post-exercise heart rate, which was observed as a health benefit. In addition, participants in the study group exhibited improved psychological well-being in addition to exhibiting an increase in personal growth after the study. Based on these findings, the authors concluded that walking programs are a means to increase physical activity of older adults aged 50 to 70 . They (walking programs) are also a means to improve the "levels of health, fitness, and well-being” (p.307) of older adults.

Chronic illnesses such as osteoarthritis, hypertension, diabetes, and peripheral vascular diseases have been found to be common among frail older adults. Even though exercise has been found to have nonpharmacologic benefits to this population, Heath \& Stuart (2002) report that the prescription of physical activity has been an underused therapy for frail older adults. The authors believe this is due to barriers, which are created by the older adult themselves, their caregivers, and their heath care providers. 
To demonstrate that primary care providers can overcome these barriers by prescribing strategic, safe and sustainable exercise programs that are geared towards the functional needs and preference of the elderly, Heath \& Stuart (2002) looked to the literature for support. The authors argued that traditional elements such as "mode of exercise, intensity of exercise, and frequency of exercise" (p.223) should be considered when prescribing exercise regimen to frail elderly. Prescription of the appropriate element of training/exercise to the frail elderly should depend on the "preserved functional skills, available resources, and perhaps most importantly, those forms of exercise that offer the most enjoyment and can be sustained" (p. 223). Including balancing and flexibility the mode of exercise was also found to prevent falls.

After a thorough review of the literature, the authors concluded that despite the existence of the barriers, primary physicians are encouraged to promote exercise as a therapeutic intervention to improve the functional fitness and overall health of frail elderly. The authors encouraged physicians to be enthused about prescribing regular exercise to their frail patients. Also, involving the frail elderly in the decision making process on the type of exercise that is best for them, is essential in getting to commit to the program. The benefits associated with incorporating exercise regimen in the treatment of the elderly do not only benefit them, but also the society in general.

A recent study has found that active lifestyle, including simple household chores (like dish washing, cooking, playing cards, etc.), could slow down older adults' cognitive decline and reduce their risks of developing Alzheimer's disease, even among those who over 80 years old. A prospective, observational cohort study by Buchman, Boyle, Yu, Shah, Wilson, et al. (2012) evaluated 716 older adults whose 2 or more annual cognitive assessment showed no presence of dementia. Each of the participants was issued a wrist Actigraphs, which recorded their 
movement for 24 hours each day for up to 10 days. The Actigraph was capable of continuously recording all activities (exercise and nonexercise physical activity) of the participants for up to 10 days. After structured annual clinical assessment and 19 cognitive tests, the study showed very interesting results.

The results indicated that engaging in a relative active lifestyle reduces the rate of older adults' cognitive decline and risk of developing Alzheimer's disease. Less than $10 \%$ (71) of the participants developed Alzheimer's disease during the study. In addition, the results showed an association between activity intensity levels and cognitive decline. Compared to the participants who engaged in the most intense activity, those who engaged in least amount of activity were almost 3 times likely to experience cognitive decline and develop Alzheimer's disease.

After reviewing the multitude of benefits that regular physical activity provides, the American College of Sports Medicine (ACSM) has recommended older adults engage in a wellrounded exercise program consisting of aerobic, stretching, strength, and balance exercises. It is important to note that these four parameters not only yield substantial health and fitness benefits, these activities also contribute to functional fitness.

\subsection{Physical Activity and Functional fitness}

In addition to the health benefits of active lifestyle, engaging in an active lifestyle also improves the functional fitness of older adults. Several studies have established the amount (a minimum of $30 \mathrm{~min}, 5 \mathrm{~d} / \mathrm{wk}$ doing moderate intensity physical activity or 20 minutes engaging in vigorous-intensity activity at least 3 days/week) of physical activity needed to improve the overall health of older adults. Unfortunately, the amount of activity necessary to maintain functional fitness is not yet established, and may be less than amounts necessary for good health. 
Functional fitness is a concept that reflects an older adult's ability to perform physical activities of daily life with relative ease (Rikli and Jones, 1990a). As noted, this concept accounts for traditional physical fitness parameters such as muscle strength, cardio-respiratory endurance, and flexibility, and also includes balance. Even in healthy adults, each component of functional fitness declines with advancing age, negatively affecting quality of life (Donato et al. (2003). For example, the age-associated decline in muscle strength is a major cause of physical disability in older people (Doherty, 2003) and decreased muscular strength and poor balance are major risk factors for falls (Rogers and Evans, 1993). Furthermore, impaired joint flexibility can negatively affect the ability to perform self-care activities such as bathing and dressing. Much attention has been focused on regular physical activity as a means to enhance health and maintain function in old age and several exercise programs have been designed to improve the parameters of fitness and, in turn, enhance function (ACSM, 1998; 1998a).

Aerobic exercises. It is established that aerobic exercises such as walking and running improve cardiorespiratory endurance in older adults with walking eliciting impact forces that are 3.6 times less than running (Torama, Erman, and Agyar, 2004), resulting in low bone-joint stress (Moreland, Richardson, Chan, O’Neill, Bellissimo, et al. (2003). Considering the orthopedic and other medical factors associated with aging, walking is an often prescribed exercise mode for older people to promote cardiorespiratory fitness (Voloshin, 1988) and, indeed, walking has been reported to be the most common physical activity reported by adults in the United States, Canada, and Europe (DiPietro, 2001).

Strength Exercises. Sarcopenia (loss of muscle mass) in aging is also well documented. Musculoskeletal weakness and disability is especially common among older women and, along with compromised flexibility and balance, contributes to functional disability and the risk of 
falls. Strength training can result in improvements in muscle size and strength in elderly men and women; and can also improve balance and gait speed in very old and frail nursing home residents, improve bone health, and decrease many of the risk factors for an osteoporotic fracture (Drewnowski and Evans (2001).

Balance Exercises. In many cases, poor postural balance is a primary risk factor for falls (Miotto, Chodzko-Zajko, Reich, and Supler, 1999; Takeshima, Tanaka, Kobayashi, Sumi, Watanabe, et al., 1993). Although sometimes difficult to define and measure, postural balance is basically the ability to maintain the body's position over its base of support, whether the base is stationary or moving (Rogers, Sherwood, Roger and Bohlken (2002). Fortunately, research indicates balance exercise programs can improve postural balance (Borg, 1982; Hunter, Wetzstein, McLafferty Jr., Zuckerman, Landers, et al. (2001) in older adults.

A cross-sectional study by Brach, Simonsick, Kritchevsky, Yaffe, and Newman (2004) used 3,075 well-functioning older adults between the ages of 70 and 79 years old in the study, which was to determine the effects of normal physical activities on older adults' functional fitness. The researchers used "modified leisure-time physical activity questionnaire" to group the participants into inactive, lifestyle active and exercise groups and the Established Populations for the Epidemiologic Studies of the Elderly (EPESE) battery was used to measure the subjects' functional fitness levels.

The results of the study indicate that engaging in even small amounts of physical activity helps slow the decline in functional fitness, older adults who engage in 20-30 minutes of moderate intensity exercise on regular basis, most of the days in a week, exhibit better health and have better functional compared to those who are less active throughout the day or those who are inactive. That is, although lifestyle activities may reduce older adults' chance of experiencing 
functional limitations, greater functional capacity is seen in older adults who engage in physical exercise. The findings of the study also indicated that both the amount and intensity of the physical activity older adults engage in are important in making them functionally fit as well as bettering their health outcomes.

Aoyagi, Park, Watanabe, Park, and Shephard (2009) conducted a study of 170 Japanese participants aged 65 to 84 years, to determine the association between functional fitness and a year of accelerometer determined physical activity. The average steps/day and the duration of moderate intensity physical activity were the variables of this study. The researchers used "preferred and maximal walking speeds, peak handgrip force, peak knee extension torque, total body sway and maximal functional reach" to measure the functional fitness of older adults. After a year of wearing the accelerometors, results indicate a significant positive relationship between daily steps and the duration of moderate intensity activities as well as the lower body functions of knee extension torque and walking speed.

Purath, Buchholz \& Kark (2009) studied the relationship between functional fitness, demographic characteristics, physical activity and health using 34 participants aged 60 years and older in a community setting. The functional fitness of the participants was measured using the validated Senior Fitness Test (SFT) protocol. The participants were asked to complete a selfreport of their demographics, general health and also the level of their physical activity during a period of one week. The results of the study revealed that older adults who reported fewer chronic conditions and better health condition had better score on the SFT measures. Also, the participants who reported to engage in more physical activity "had significantly better upper and lower body strength, aerobic endurance, and dynamic balance" Purath et al. (2009). 


\section{CHAPTER 3}

\section{METHODOLOGY}

\subsection{Study Population and Screening}

A total of one hundred and twenty five older women between the ages of 55 and 95 years old $(73.42 \pm 8.84$ yrs) were recruited from two mid-western communities. The Wichita State University Institutional Review Board approved the study protocol, and each participant read and signed an informed consent document (Appendix A). Each participant was screened with the EASY (Exercise and Screening for You) questionnaire (Appendix B). Physician's permission was requested from participants whose EASY results showed they were not fit to participate in the study (Appendix C). Participants whose physical and mental health prevented them from properly participating in the study were excluded from the study.

\subsection{Procedure}

After the screening process, each participant met with study investigators to complete a functional fitness assessment and then wore a locked accelerometer for 2 weeks during all walking hours. Participants were instructed to take off the accelerometer to bathe or swim. The accelerometer was worn at waist, clipped to a belt or clothing, and centered over the dominant foot. Prior to accelerometer distribution, each participant's functional fitness was measured using the Rikli \& Jones (1999a) Functional Fitness Assessment, a validated senior fitness test protocol. The assessments were conducted using individual stations and participants were asked to go from one station to another, in an orderly manner, where they were assessed. During the walking test, participants walked in small groups, and each participant's performance was 
measured after the group walk was complete. Following the functional fitness assessment accelerometers were distributed to participants with instructions to return it in two weeks.

\subsection{Assessment}

I. Demographics

Each participant answered demographic questionnaire that asked about variables such as current age, ethnicity, marital status, education background, and household income. There was also self-reports of alcohol consumption, smoking status, personal history of disease, and medication use (Appendix D).

II. $\quad$ Active lifestyle assessment

Kenz Lifecorder accelerometers (ACCEL) (Suzuken Company, Nagoya, Japan) were used to assess the active lifestyle levels of the participants. The ACCEL records physical activity intensities in ten different levels - zero to nine, with higher numbers indicating higher intensity. The intensity levels are determined via a proprietary filtering process that considers frequency and magnitude of accelerations. Previously developed and validated formulas were used to calculate time spent in each intensity: $0=$ nonambulatory, 1-3 = light, 4-6 = moderate and 7-9 = vigorous. The ACCEL is uniaxial, small in size (62.5 $\mathrm{mm} \square 46.5 \mathrm{~mm} \square 26.0 \mathrm{~mm})$, light in weight (40 g), and powered by a lithium battery (CR2032, 3V). According to the device, acceleration is sampled every four seconds and recorded at two minute intervals (Crouter, et al., 2003).

The daily activity summary files of each participant were downloaded to an Excel spreadsheet to determine physical activity intensities. Time spent in each intensity 
(sedentary, low, moderate, vigorous) was calculated. A 5 day average of time spent in MVPA was organized into 4 groups.

\section{Functional fitness assessment}

The Rikli \& Jones (1999a) validated Functional Fitness test protocol was used to assess the functional fitness performance of the participants: 30-sec Chair Stand, 30-sec Arm Curl, Chair Sit and Reach, Scratch Test, 8' Up and Go, and 6-Minute Walk.

1. 30-Second Chair Stand: The purpose of this assessment was to measure lower body strength. The test began with the participant seated in the middle of the chair, back straight, and feet approximately shoulder width apart and flat on the floor. Arms were crossed and held against the chest. At the signal "go" the participant rose to a full stand (body erect and straight) and then returned back to the initial seated position. The participant was encouraged to complete as many full stands as possible within a 30-second time limit. Participants were given two or three practice repetitions. The score was the total number of stands executed correctly within 30 seconds. If the participant was more than halfway up upon completion of the 30 seconds, it counted as a full stand.

2. 30-Second Arm Curl: The purpose of this assessment was to measure upper body strength. The participant was seated on a chair, back straight and feet flat on the floor, and with the dominant side of the body close to the edge. The weight was held at the side in the dominant hand. The test began with the arm in the down position beside the chair, perpendicular to the floor. At the signal "go" the participant curled the arm through a full range of motion, and then returned to the fully extended position in a controlled manner. The participant repeated this movement as many 
times and as quickly as possible in 30 -seconds. The score was the total number of curls made correctly within 30 seconds. If the participant's arm was more than halfway up at the end of 30 seconds, then it counted as a completed curl. A 5-lb dumbbell was used by the participants.

3. Chair Sit and Reach Test: The purpose of this assessment was to assess lower body (primarily hamstring) flexibility. The test began with the participant sitting on the front edge position of a chair. Keeping one leg bent and foot on the floor, the other leg (the preferred leg*) was extended straight in front of the hip, with heel on the floor and foot flexed. With the extended leg as straight as possible, the participant slowly bent forward at the hip joint sliding the hands (one on top of the other with the tips of the middle fingers even) down the extended leg in an attempt to touch the toes. The reach was held for two seconds. A ruler was used to measure the number of inches (nearest $1 / 2$ inch) a person is short of reaching the toes (minus score) or reaches beyond the toes (plus score). The participant was given two practice trials. The score was the best measure of two trials. * The preferred leg is defined as the one that results in the better score.

4. $\quad$ ' Up and Go: The purpose of this assessment was to measure physical mobility involving speed, agility, and dynamic balance. The test began with the participant fully seated in the chair, hands on thighs, and feet flat on the floor. The participant was allowed to push off the sides or arms of the chair to aid in getting up from the chair. On the signal "go", each participant was instructed to stand up from the chair as quickly as possible, walk around a cone placed 8 feet in front of the chair, and return to a seated position in the chair. The participant was told the test was timed 
and that the object was to walk around the cone as fast as possible (without running) and return to a seated position. A timed score was recorded from moment the signal "go" was given until the participant returned to a seated position on the chair. The participant was allowed to walk through the test for practice. The participant's score was recorded as the best of the two most consistent times measured.

5. Scratch Test: The purpose of this assessment was to assess upper body (shoulder) flexibility. In a standing position, the participant placed the preferred hand* over the same shoulder and reached as far as possible down the middle of the back, palm down and fingers extended. Hand of other arm was placed behind back, palm up, reaching up as far as possible in an attempt to touch (or overlap) the extended middle fingers of both hands. The distance of overlap, or distance between the tips of the middle fingers was measured to the nearest $1 / 2$ inch. Minus scores (-) were given to represent the distance short of touching middle fingers; plus scores (+) represent the degree of overlap of middle fingers. The "best" score was used to evaluate performance. *The preferred hand is defined as the one that results in the better score.

6. 12-Minute Walk: The purpose of this test was to assess aerobic endurance. The test involved assessing the maximum distance that can be walked in 12 minutes along a 50-meter course, marked into 5-meter segments. Participants continuously walked around a measured lap throughout the 12-minute period, trying to cover as much distance as possible. On the signal "go", participants were instructed to walk as fast as possible (not run) the marked distance around the cones as many times as they can within the time limit. If necessary, participants could stop and rest, sit on chairs 
provided, then resume walking. The score was the total number of yards walked in 12 minutes to the nearest 5 meter indicator.

\subsection{Data Groups}

Time Spent in Moderate Intensity. To address the hypothesis that time spent in moderate intensity physical activity will impact functional fitness measures, a 5 day average of time spent in moderate intensity physical activity was organized into 4 groups: 0:00-9:59 min, 10:00-19:59 min, 20:00-29:59 min, and 30:00 plus min (In Table 3.1).

TABLE 3.1

5 DAY AVERAGE OF TIME SPENT IN MODERATE INTENSITY PHYSICAL ACTIVITY BY GROUP

\begin{tabular}{|c|l|c|}
\hline Group Name & Group (min) & n \\
\hline $10 \mathrm{~min}$ & $0: 00-9: 59$ & 58 \\
\hline $20 \mathrm{~min}$ & $10: 00-19: 59$ & 27 \\
\hline $30 \mathrm{~min}$ & $20: 00-29: 59$ & 14 \\
\hline $30+\mathrm{min}$ & $30: 00+$ & 22 \\
\hline
\end{tabular}

\subsection{Data Analysis}

Data analysis was completed using the statistical software program SPSS for Windows V.16.0 (SPSS Inc., Chicago, IL). Data were expressed as mean \pm SD and screened for outliers, and the assumptions of normality and homoscedasticity. Assumptions of homogeneity of variance and sphericity were evaluated. Frequency distributions were calculated to examine the number of participants meeting ACSM recommendation for MVPA as well as the number of participants with normal functional fitness as determined by the Rikli and Jones (1999a) classification. Functional fitness scores were grouped based on Rikli and Jones (1999a)'s 
validated Senior Fitness Test Normal Range Scores. The Senior Fitness Test evaluates older adults' functional fitness performance and the score is based on the participant's age and the number of time s/he is able to perform each activity (Chair Stands, Arm Curls, 6-Min Walk, Chair Sit and Reach, Back Scratch, 8-Ft Up-\&-Go). Those scoring below range are considered below average for their age, those scoring within range are considered average for their age, and those scoring above range are considered above average for their age. Correlations between 5 day MVPA averages and Senior Fitness Test measures (Chair Stands, Arm Curls, 6-Min Walk, Chair Sit and Reach, Back Scratch, 8-Ft Up-\&-Go) were calculated to determine the relationship between time spent in MVPA and functional fitness. To determine cut-off points, moderate intensity group comparisons were made using one-way ANOVA with follow-up post hoc analysis. A probability value of less than 0.05 was considered statistically significant and a Bonferroni adjustment was used to correct for multiple measurements. 


\section{CHAPTER 4}

\section{RESULTS}

\subsection{Normality and Assumptions}

Non-significant Kolomogorov-Smirnov tests indicated all variables were normally distributed. In addition, histograms and normal Q-Q plots revealed normal distributions of variables in all groups. Assumptions of homogeneity of variance and sphericity were evaluated and not violated.

\subsection{Participant Characteristics}

One hundred and twenty five women completed the assessments. Participants characteristics are as follows: Age (73.42 $\pm 8.84 \mathrm{yrs})$, Height $(63.22 \pm 2.73 \mathrm{~cm})$, Weight $(159.17$ $\pm 33.32 \mathrm{lb})$, and Body Mass Index $(28.64 \pm 6.29)$. With respect to the number of participants meeting ACSM recommendations, only 17.6\% (22 of 125) of participants met this recommendation. With respect to functional fitness, normal functional fitness classifications were made using guidelines set by Rikli and Jones (1999a). Participants scoring higher or lower than the Rikli and Jones normal classification were noted as below normal or above normal (Table 4.1). 
TABLE 4.1

\section{FUNCTIONAL FITNESS CLASSIFICATION}

\begin{tabular}{|c|c|c|c|c|c|c|c|c|c|c|c|c|c|c|}
\hline \multirow[t]{2}{*}{ Age Group } & \multicolumn{2}{|c|}{ BMI } & \multicolumn{2}{|c|}{$\begin{array}{c}\text { Chair } \\
\text { Stands }\end{array}$} & \multicolumn{2}{|c|}{$\begin{array}{l}\text { Arm } \\
\text { Curls }\end{array}$} & \multicolumn{2}{|c|}{$\begin{array}{l}\text { 6-Min } \\
\text { Walk }\end{array}$} & \multicolumn{2}{|c|}{$\begin{array}{l}\text { Sit-\&- } \\
\text { Reach }\end{array}$} & \multicolumn{2}{|c|}{$\begin{array}{c}\text { Back } \\
\text { Scratch }\end{array}$} & \multicolumn{2}{|c|}{$\begin{array}{c}\text { Up-\&- } \\
\text { Go }\end{array}$} \\
\hline & $\mathbf{n}$ & $\%$ & $\mathbf{n}$ & $\%$ & $\mathbf{n}$ & $\%$ & $\mathbf{n}$ & $\%$ & $\mathbf{n}$ & $\%$ & $\mathbf{n}$ & $\%$ & $\mathbf{n}$ & $\%$ \\
\hline \multicolumn{15}{|l|}{55 - 65 years $(n=24)$} \\
\hline Below Normal & 0 & $0 \%$ & 4 & $17 \%$ & 0 & $0 \%$ & 6 & $25 \%$ & 5 & $21 \%$ & 14 & $58 \%$ & 10 & $42 \%$ \\
\hline Normal & 7 & $29 \%$ & 13 & $54 \%$ & 8 & $33 \%$ & 6 & $25 \%$ & 11 & $46 \%$ & 10 & $42 \%$ & 7 & $29 \%$ \\
\hline Above Normal & 17 & $71 \%$ & 7 & $29 \%$ & 16 & $67 \%$ & 11 & $46 \%$ & 8 & $33 \%$ & 0 & $0 \%$ & 7 & $29 \%$ \\
\hline \multicolumn{15}{|l|}{ 65-69 years $(n=25)$} \\
\hline Below Normal & 0 & $0 \%$ & 4 & $16 \%$ & 0 & $0 \%$ & 7 & $28 \%$ & 5 & $20 \%$ & 12 & $48 \%$ & 6 & $24 \%$ \\
\hline Normal & 7 & $28 \%$ & 15 & $60 \%$ & 8 & $32 \%$ & 9 & $36 \%$ & 16 & $64 \%$ & 8 & $32 \%$ & 13 & $52 \%$ \\
\hline Above Normal & 18 & $72 \%$ & 6 & $24 \%$ & 17 & $68 \%$ & 8 & $32 \%$ & 3 & $12 \%$ & 5 & $20 \%$ & 6 & $24 \%$ \\
\hline \multicolumn{15}{|l|}{ 70-74 years $(n=27)$} \\
\hline Below Normal & 0 & $0 \%$ & 4 & $15 \%$ & 3 & $11 \%$ & 3 & $11 \%$ & 6 & $22 \%$ & 12 & $44 \%$ & 4 & $15 \%$ \\
\hline Normal & 4 & $15 \%$ & 18 & $67 \%$ & 11 & $41 \%$ & 19 & $70 \%$ & 16 & $59 \%$ & 10 & $37 \%$ & 15 & $56 \%$ \\
\hline Above Normal & 23 & $85 \%$ & 5 & $19 \%$ & 13 & $48 \%$ & 5 & $19 \%$ & 4 & $15 \%$ & 5 & $19 \%$ & 8 & $30 \%$ \\
\hline \multicolumn{15}{|l|}{ 75-79 years $(n=22)$} \\
\hline Below Normal & 0 & $0 \%$ & 2 & $9 \%$ & 1 & $5 \%$ & 5 & $23 \%$ & 5 & $23 \%$ & 13 & $59 \%$ & 4 & $18 \%$ \\
\hline Normal & 12 & $55 \%$ & 14 & $64 \%$ & 12 & $55 \%$ & 7 & $32 \%$ & 11 & $50 \%$ & 3 & $14 \%$ & 9 & $41 \%$ \\
\hline Above Normal & 9 & $41 \%$ & 5 & $23 \%$ & 9 & $41 \%$ & 10 & $45 \%$ & 6 & $27 \%$ & 6 & $27 \%$ & 9 & $41 \%$ \\
\hline \multicolumn{15}{|l|}{$80-84$ years $(n=16)$} \\
\hline Below Normal & 0 & $0 \%$ & 3 & $19 \%$ & 2 & $13 \%$ & 3 & $19 \%$ & 4 & $25 \%$ & 5 & $31 \%$ & 0 & $0 \%$ \\
\hline Normal & 7 & $44 \%$ & 9 & $56 \%$ & 4 & $25 \%$ & 5 & $31 \%$ & 11 & $69 \%$ & 5 & $31 \%$ & 9 & $56 \%$ \\
\hline Above Normal & 9 & $56 \%$ & 4 & $25 \%$ & 10 & $63 \%$ & 7 & $44 \%$ & 1 & $6 \%$ & 6 & $38 \%$ & 6 & $38 \%$ \\
\hline \multicolumn{15}{|l|}{$85-89$ years $(n=8)$} \\
\hline Below Normal & 0 & $0 \%$ & 3 & $38 \%$ & 1 & $13 \%$ & 3 & $38 \%$ & 3 & $38 \%$ & 7 & $88 \%$ & 2 & $25 \%$ \\
\hline Normal & 2 & $25 \%$ & 3 & $38 \%$ & 5 & $63 \%$ & 2 & $25 \%$ & 4 & $50 \%$ & 1 & $13 \%$ & 6 & $75 \%$ \\
\hline Above Normal & 5 & $63 \%$ & 1 & $13 \%$ & 2 & $25 \%$ & 2 & $25 \%$ & 1 & $13 \%$ & 0 & $0 \%$ & 0 & $0 \%$ \\
\hline \multicolumn{15}{|l|}{$90+\operatorname{years}(n=3)$} \\
\hline Below Normal & 0 & $0 \%$ & 1 & $33 \%$ & 0 & $0 \%$ & 0 & $0 \%$ & 0 & $0 \%$ & 1 & $33 \%$ & 0 & $0 \%$ \\
\hline Normal & 3 & $100 \%$ & 1 & $33 \%$ & 2 & $67 \%$ & 3 & $100 \%$ & 3 & $100 \%$ & 2 & $67 \%$ & 2 & $67 \%$ \\
\hline Above Normal & 0 & $0 \%$ & 1 & $33 \%$ & 1 & $33 \%$ & 0 & $0 \%$ & 0 & $0 \%$ & 0 & $0 \%$ & 1 & $33 \%$ \\
\hline \multicolumn{15}{|l|}{ TOTAL $(n=125)$} \\
\hline Below Normal & 0 & $0 \%$ & 21 & $17 \%$ & 7 & $6 \%$ & 27 & $22 \%$ & 28 & $23 \%$ & 64 & $51 \%$ & 26 & $21 \%$ \\
\hline Normal & 42 & $34 \%$ & 73 & $59 \%$ & 50 & $40 \%$ & 51 & $42 \%$ & 72 & $59 \%$ & 39 & $31 \%$ & 61 & $49 \%$ \\
\hline Above Normal & 81 & $66 \%$ & 29 & $24 \%$ & 68 & $54 \%$ & 43 & $36 \%$ & 23 & $19 \%$ & 22 & $18 \%$ & 37 & $30 \%$ \\
\hline
\end{tabular}




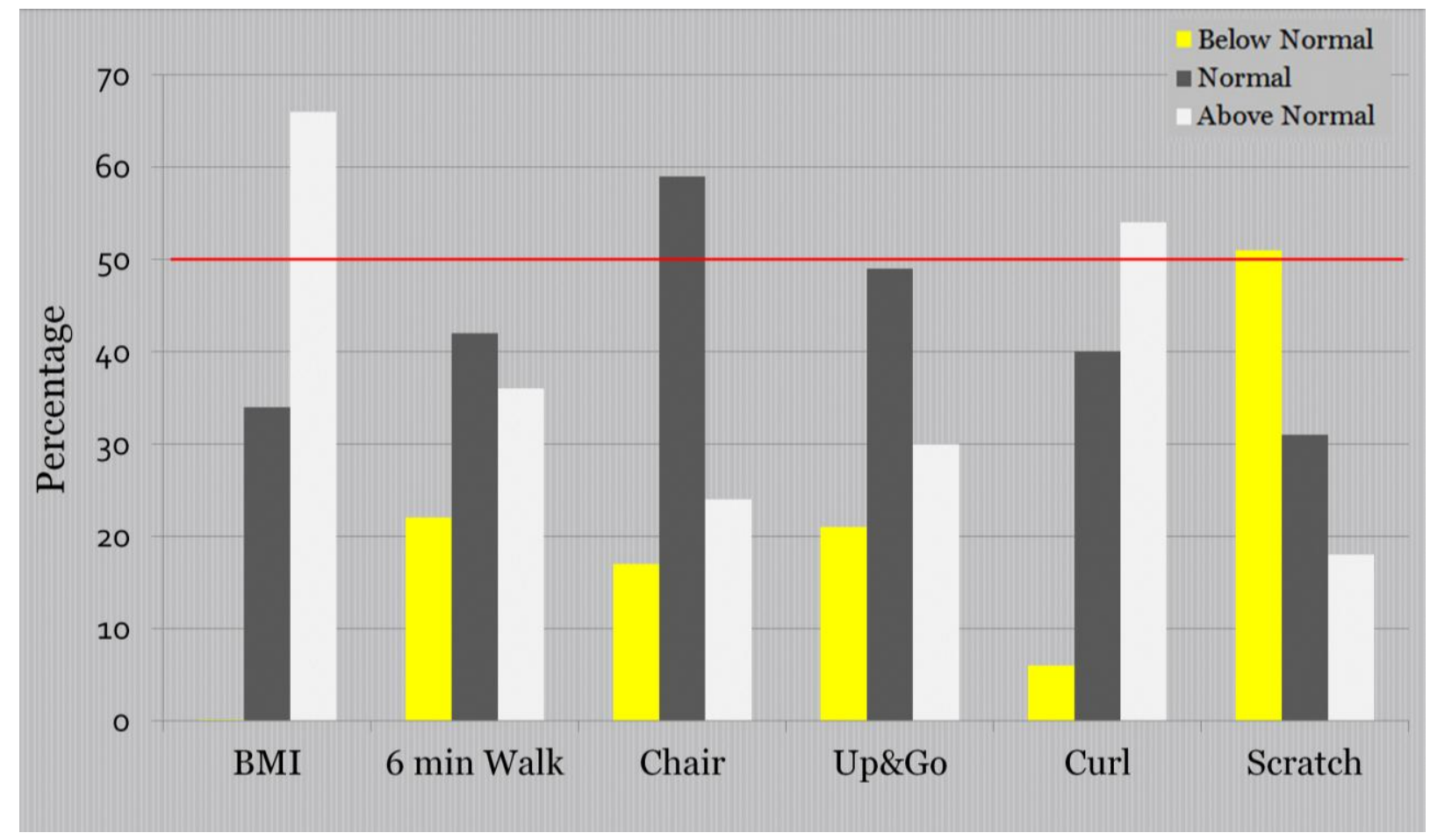

FIGURE 4.1 FUNCTIONAL FITNESS CLASSIFICATION

Functional fitness classification by age group is provided in Table 4.1. In general, approximately half of the participants were classified as normal, with the exception of BMI (34\%) and back scratch (31\%). Moreover, approximately $1 / 4$ of participants were classified as below normal and $1 / 4$ were classified as above normal. BMI was an exception with $66 \%$ of participants being above normal, as well as arm curls where participants performed above normal (54\%) compared to their age group, and back scratch in which participants upper extremity flexibility was below normal (51\%). 


\subsection{Relationship between MVPA and Functional Fitness}

Pearson product moment correlations were used to determine if a relationship existed between the participants 5 day MVPA, functional fitness, age and weight (Table 4.2). The correlation coefficients indicated that all variables were significantly related to MVPA, although the relationship was negligible for sit and reach $(\mathrm{r}=0.19, \mathrm{p} \leq 0.05)$, and weak for back scratch $(\mathrm{r}$ $=0.23, \mathrm{p} \leq 0.01), \operatorname{arm} \operatorname{curl}(\mathrm{r}=0.23, \mathrm{p} \leq 0.01)$ and age $(\mathrm{r}=-0.28, \mathrm{p} \leq 0.001)$. The strongest relationships were found between MVPA and the 6 min walk $(r=0.52, p \leq 0.001)$, chair stands $(\mathrm{r}=0.46, \mathrm{p} \leq 0.001)$, and the up \& go $(\mathrm{r}=-0.44, \mathrm{p} \leq 0.001)$. A moderate relationship was noted between MVPA and BMI $(\mathrm{r}=-0.31, \mathrm{p} \leq 0.001)$ and weight $(\mathrm{r}=-0.30, \mathrm{p} \leq 0.001)$. 
TABLE 4.2

CORRELATION COEFFICIENTS

\begin{tabular}{|c|c|c|c|c|c|c|c|c|c|c|c|}
\hline & & MVPA & Age & Weight & BMI & Chair & 6 Min Walk & Up \& Go & Arm Curl & Sit \& Reach & Back Scratch \\
\hline \multirow[t]{3}{*}{ MVPA } & Pearson Correlation & & & & & & & & & & \\
\hline & Sig. (2-tailed) & & & & & & & & & & \\
\hline & $\mathrm{N}$ & & & & & & & & & & \\
\hline \multirow[t]{3}{*}{ Age } & Pearson Correlation & $-.283^{* *}$ & & & & & & & & & \\
\hline & Sig. (2-tailed) & .001 & & & & & & & & & \\
\hline & $\mathrm{N}$ & 125 & & & & & & & & & \\
\hline \multirow[t]{3}{*}{ Wt } & Pearson Correlation & $-.304^{* *}$ & -.340 ** & & & & & & & & \\
\hline & Sig. (2-tailed) & .001 & .000 & & & & & & & & \\
\hline & $\mathrm{N}$ & 125 & 125 & & & & & & & & \\
\hline \multirow[t]{3}{*}{ BMI } & Pearson Correlation & $-.306^{* *}$ & -.232 * & $.786 * *$ & & & & & & & \\
\hline & Sig. (2-tailed) & .001 & .010 & .000 & & & & & & & \\
\hline & $\mathrm{N}$ & 122 & 122 & 122 & & & & & & & \\
\hline \multirow[t]{3}{*}{ Chair } & Pearson Correlation & $.464^{* *}$ & $-.413^{* *}$ & -.187 * & -.185 * & & & & & & \\
\hline & Sig. (2-tailed) & .000 & .000 & .038 & .043 & & & & & & \\
\hline & $\mathrm{N}$ & 123 & 123 & 123 & 120 & & & & & & \\
\hline $6 \mathrm{Min}$ & Pearson Correlation & $.523^{* *}$ & $-.365^{* *}$ & -.299 ** & $-.355^{* *}$ & $.541^{* *}$ & & & & & \\
\hline \multirow[t]{2}{*}{ Walk } & Sig. (2-tailed) & .000 & .000 & .001 & .000 & .000 & & & & & \\
\hline & $\mathrm{N}$ & 121 & 121 & 121 & 118 & 119 & & & & & \\
\hline \multirow[t]{3}{*}{ Up \& Go } & Pearson Correlation & -.436 ** & $.432^{* *}$ & .178 * & .168 & -.623 ** & $-.641^{* *}$ & & & & \\
\hline & Sig. (2-tailed) & .000 & .000 & .047 & .065 & .000 & .000 & & & & \\
\hline & $\mathrm{N}$ & 125 & 125 & 125 & 122 & 123 & 121 & & & & \\
\hline \multirow[t]{3}{*}{ Curl } & Pearson Correlation & $.223^{*}$ & $-.368^{* *}$ & .117 & .076 & .506 ** & $.459^{* *}$ & -.538 ** & & & \\
\hline & Sig. (2-tailed) & .012 & .000 & .194 & .407 & .000 & .000 & .000 & & & \\
\hline & $\mathrm{N}$ & 125 & 125 & 125 & 122 & 123 & 121 & 125 & & & \\
\hline \multirow[t]{3}{*}{ Reach } & Pearson Correlation & $.191 *$ & -.168 & -.183 * & $-.277^{\star *}$ & .145 & .232 * & -.170 & .088 & & \\
\hline & Sig. (2-tailed) & .034 & .063 & .042 & .002 & .112 & .011 & .060 & .335 & & \\
\hline & $\mathrm{N}$ & 123 & 123 & 123 & 120 & 121 & 120 & 123 & 123 & & \\
\hline \multirow[t]{3}{*}{ Scratch } & Pearson Correlation & $.227^{*}$ & -.070 & $-.476^{* *}$ & $-.497^{\star *}$ & $.197^{*}$ & $.397^{* *}$ & $-.483^{* *}$ & .180 * & $281^{* *}$ & \\
\hline & Sig. (2-tailed) & .011 & .439 & .000 & .000 & .029 & .000 & .000 & .045 & .002 & \\
\hline & $\mathrm{N}$ & 125 & 125 & 125 & 122 & 123 & 121 & 125 & 125 & 123 & \\
\hline
\end{tabular}

** Correlation is significant at the 0.01 level (2-tailed). ${ }^{*}$ Correlation is significant at the 0.05 level (2-tailed). 


\subsection{Moderate Intensity Cut-Off Points}

To determine if engaging in an active lifestyle is associated with higher functional fitness participants were grouped by their time spent in moderate intensity physical activity to determine a cut-off on improvement observed in functional fitness. MVPA group comparisons were made using one-way ANOVAs with follow-up Post Hoc analysis. The point at which no difference occurred between MVPA groups indicated additional time spent in MVPA did not improve that functional fitness measure. The same analysis was also conducted for weight and BMI.

The results revealed significant differences between groups on all measures except sit and reach (Table 4.3). The one-way ANOVA indicated a threshold of 20 minutes for the 6 min walk $(\mathrm{F}=16.72, \mathrm{p} \leq 0.001)$, chair stand $(\mathrm{F}=14.06, \mathrm{p} \leq 0.001)$, and up $\&$ go $(\mathrm{F}=13.36, \mathrm{p} \leq 0.001)$. For all 3 lower body functional fitness measures, the follow-up post hoc revealed that the 10 minute group was significantly different from all other groups $(\mathrm{p} \leq 0.01)$. However, a cut-off was observed for the 20 minute group. Although the 20 minute group was different from the 10 minute group, there was no difference between the 30 minute and 30+ minute groups, suggesting that engaging in more than 19:59 minutes of MVPA yields no additional statistical gain on the 6 min walk, chair stand, and up \& go. With regard to upper body strength and flexibility, less than 10 min of MVPA is detrimental to performance. The one-way ANOVA for arm curl $(\mathrm{F}=5.42, \mathrm{p}$ $\leq 0.01)$ and back scratch $(\mathrm{F}=2.62, \mathrm{p} \leq 0.05)$ were significant. The follow-up post hocs revealed a cut-off for the 10 minute group, in that the 10 minute group was different from all other groups (20 minute, 30 minute and 30+ minute groups). 
TABLE 4.3

MODERATE INTENSITY CUT-OFF POINTS

\begin{tabular}{|c|c|c|c|c|c|c|c|c|}
\hline $\begin{array}{c}\text { MVPA } \\
(\text { min) }\end{array}$ & $\mathbf{n}$ & $\begin{array}{c}\text { Average } \\
\text { Time (min) }\end{array}$ & Range & $\begin{array}{c}6 \text { min } \\
\text { Walk }(y d) \\
\end{array}$ & Chair (\#) & $\begin{array}{c}\text { Up \& Go } \\
(\mathbf{s})\end{array}$ & Curl (\#) & Scratch (in) \\
\hline $0: 00-9: 59$ & 58 & $3: 42$ & $0: 02-9: 58$ & $462 \pm 137 *$ & $11 \pm 3.5^{*}$ & $7.05 \pm 2.24 *$ & $16.0 \pm 5.0$ & $9.7 \pm 13.54$ \\
\hline 10:00-19:59 & 27 & $14: 37$ & $10: 18-19: 43$ & $538 \pm 174 *$ & $14 \pm 3.0^{*}$ & $5.56 \pm 1.16^{*}$ & $20.0 \pm 6.0 \dagger$ & $6.48 \pm 8.35 \dagger$ \\
\hline 20:00-29:59 & 14 & $24: 39$ & $20: 06-27: 52$ & $607 \pm 95$ & $15 \pm 4.0$ & $5.41 \pm 1.19$ & $20.0 \pm 6.5 \dagger$ & $3.89 \pm 8.78 \dagger$ \\
\hline 30:00+ & 22 & $48: 38$ & $31: 24-2: 17: 07$ & $687 \pm 90$ & $16 \pm 4.5$ & $4.52 \pm 0.95$ & $20.5 \pm 4.0 \dagger$ & $2.91 \pm 6.32 \dagger$ \\
\hline
\end{tabular}

* different from 20:00min $(\mathrm{p}<.05) \dagger$ different from 0:00 $\min (\mathrm{p}<.05)$

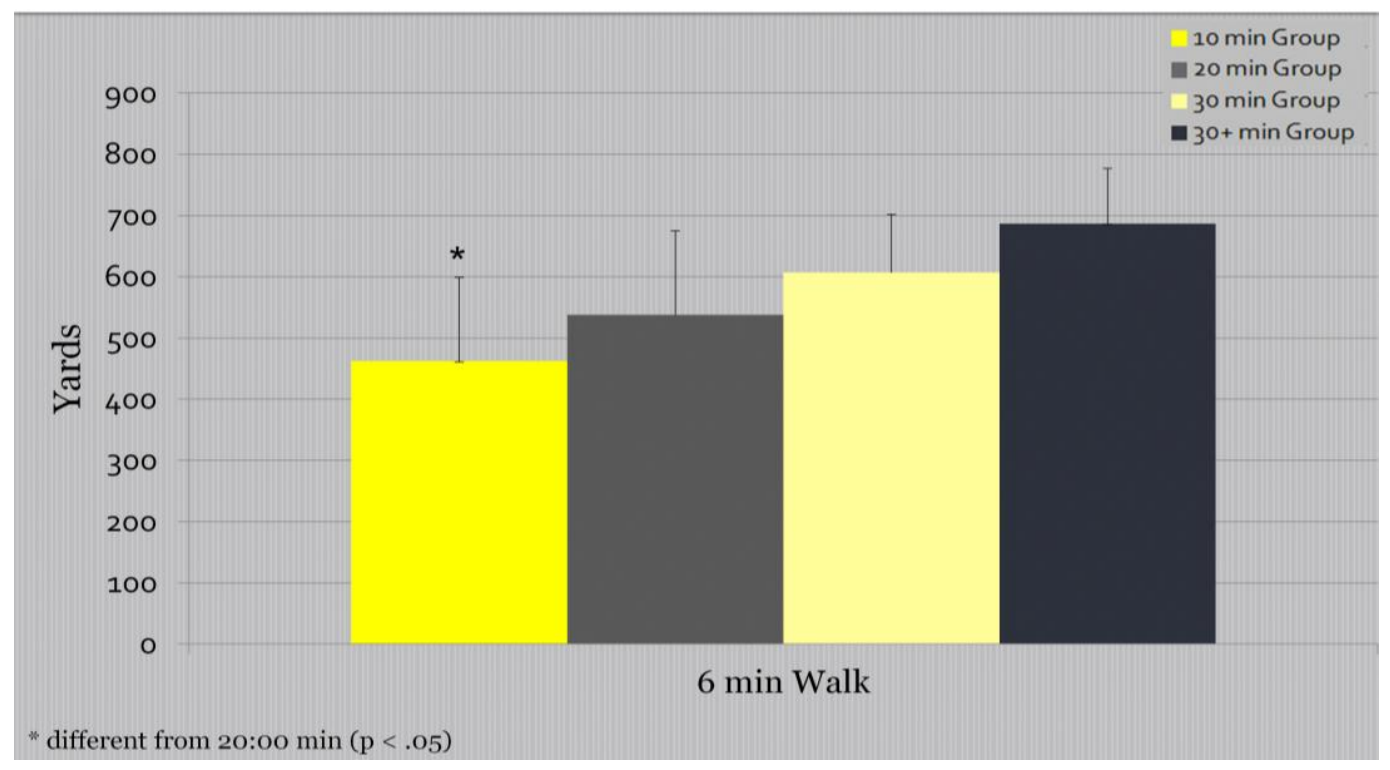

FIGURE 4.2 MODERATE INTENSITY CUT-OFF POINTS: 6 MINUTES WALK 


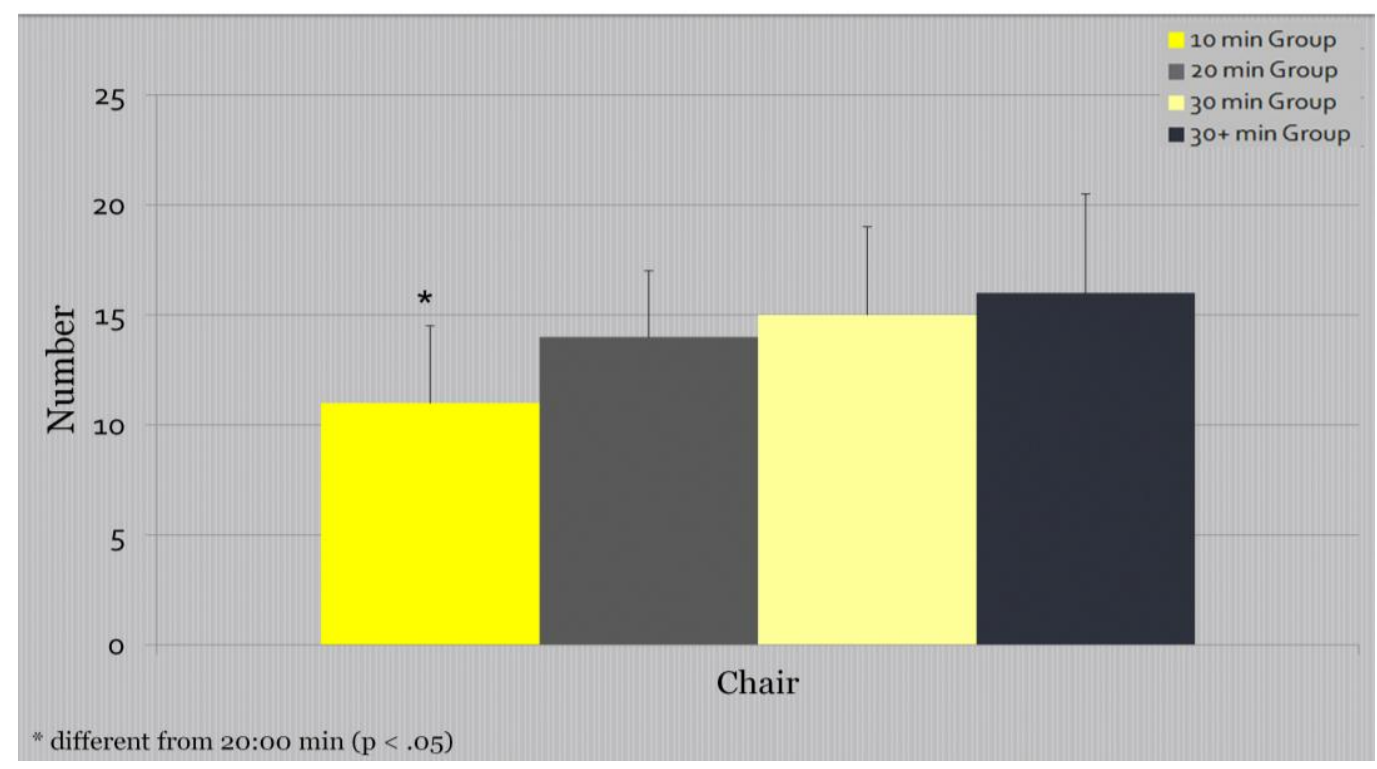

FIGURE 4.3 MODERATE INTENSITY CUT-OFF POINTS: CHAIR STANDS

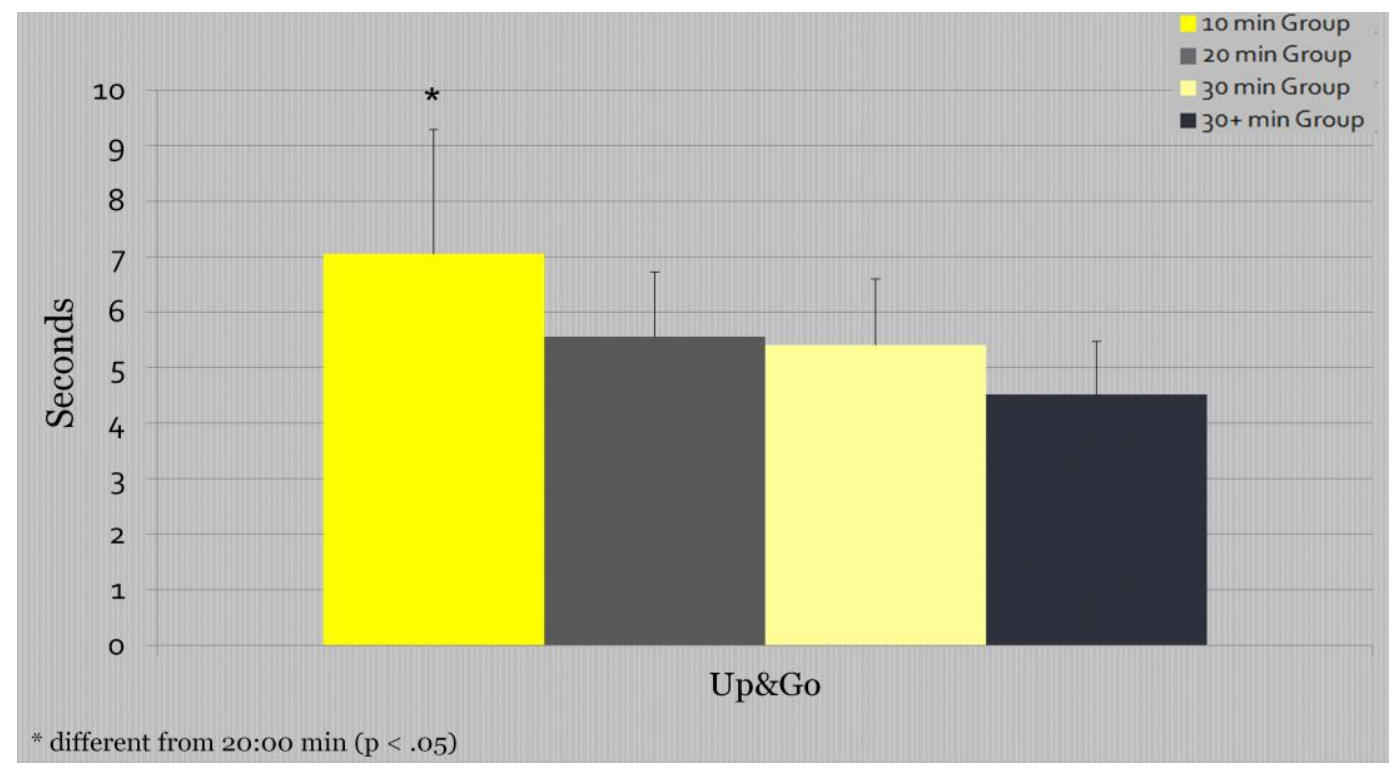

FIGURE 4.4 MODERATE INTENSITY CUT-OFF POINTS: UP \& GO 


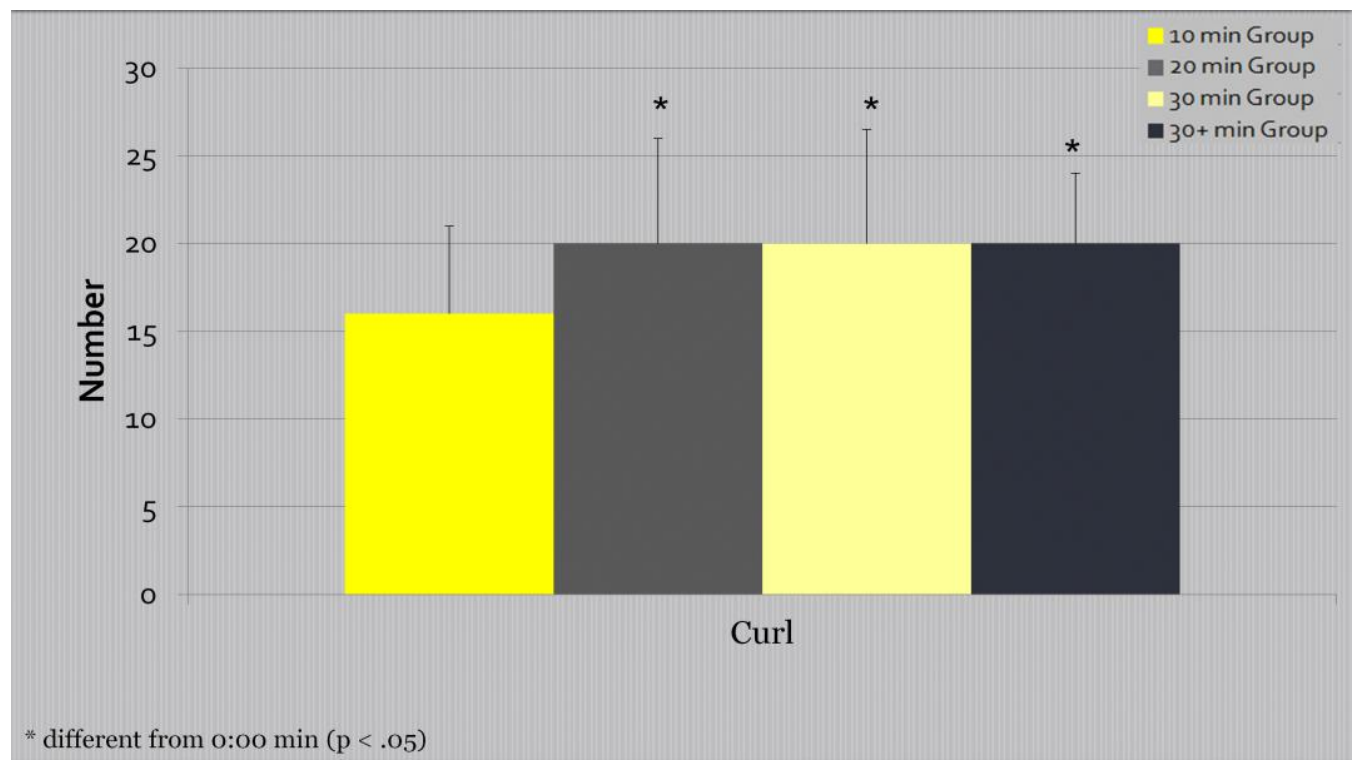

FIGURE 4.5 MODERATE INTENSITY CUT-OFF POINTS: ARM CURL

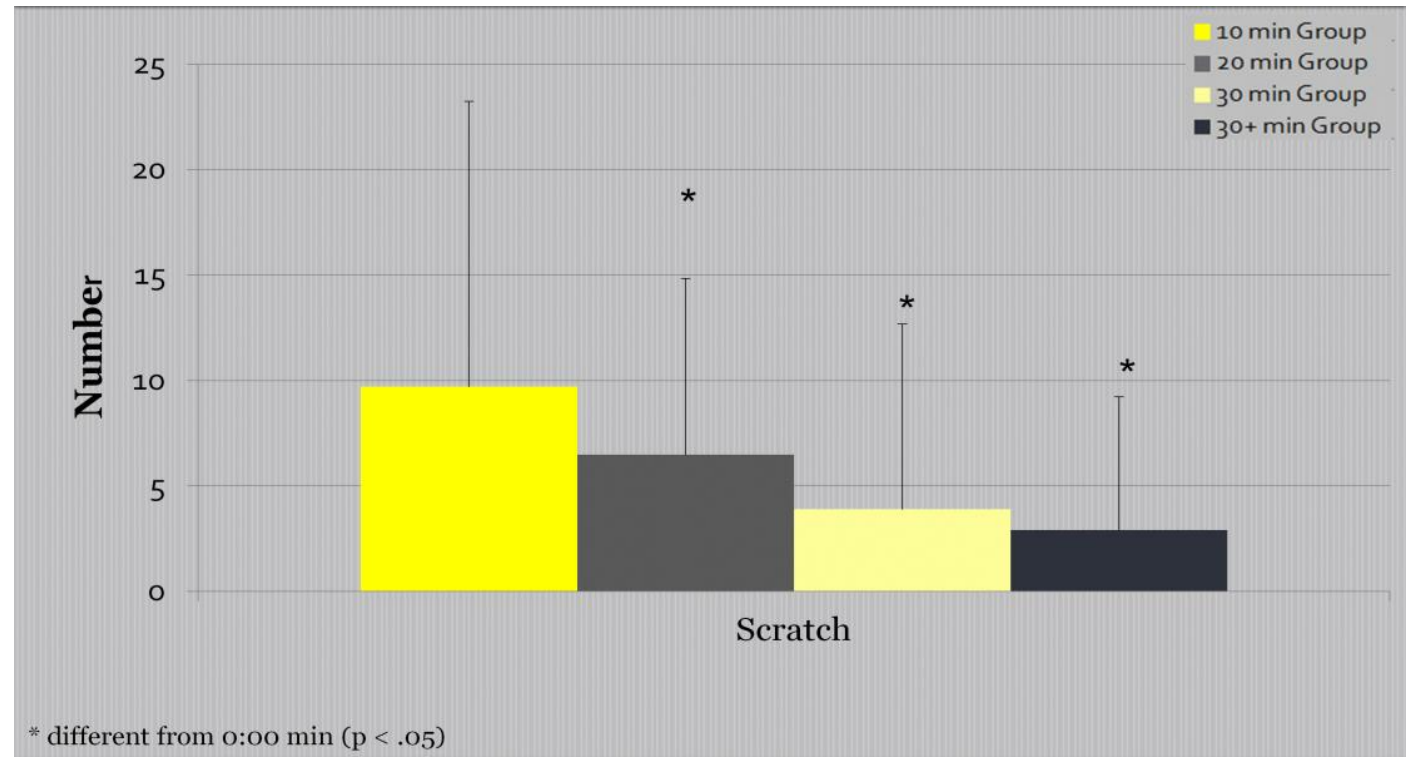

FIGURE 4.6 MODERATE INTENSITY CUT-OFF POINTS: BACK SCRATCH 


\section{CHAPTER 5}

\section{DISCUSSION}

Individual lifestyle choices, not genetic inheritance, have been documented as the major influence on successful aging; with physical active lifestyle being one of the contributory factors to successful aging (CDC, 2001). Physical activity prevents many primary and secondary chronic disease risk factors, chronic diseases, and disabling conditions that are associated with older adults. It also delays both the onset of functional limitation and loss of independence among older adults (CDC, 2001). Ferrucci et al. (2000) report that compared to inactive, nonsmoking women aged 65 ; highly active, nonsmoking women 65 years have nearly 6 years active life expectancy. The American Academy of Rheumatologists has recommended physical activity in arthritis management. A study by Kovar et al. (1992) reported that regular physical activity (e.g. walking) reduces pain and improves function among people with arthritis in the knees, and Campell et al. (1997) has documented a 58\% reduction in falls among older women who engage in exercise programs.

According to the Physical Activity Guidelines for Americans (2008), being physically active on a regular basis helps in the prevention of osteoporosis. It also helps to decrease older adults' risk of falling and improves their cognitive abilities, improves their mood and helps them sleep better, increases their chance of enjoying healthier and longer lives, among other benefits. In agreement with the above, Brach et al. (2004) have also documented that physical activity improves the overall well-being of older adults. In addition, they have also documented that moderate lifestyle activities may reduce older adults' chances of functional limitations.

Moderate intensity walking programs have been shown to attenuate functional fitness deterioration associated with aging (Morgan et al., 2010). Maintaining functional fitness helps 
older adults to continue to perform activities of daily living (personal care), and instrumental activities of daily living (shopping, preparing meals, driving, etc.); all of which will allow them to continue to live independently and remain in their homes (Rikli \& Jones,1999a). As such, older population should be encouraged to engage in, at least, 20-minute of moderate intensity physical activity. Engaging in moderate intensity physical activity will help slow the decline of functional impairment by maintaining lower body strength, a loss of which often lead to falls and physical frailty (Griffin, 2012.

There is other evidence suggesting additional benefits result from engaging in active lifestyle activities. The 2008 Physical Activity Guidelines for Americans has documented that longer and harder exercise could result in even greater benefits. This recommendation supports a study by Abbott el al (2004), which has shown that, in addition to reducing their prevalence of diabetes risk and coronary heart disease, older adult men who walk a total of 2 miles/day are 1.8folds less likely to develop dementia. A study by Tanasescu et al. (2002) has also been supported by the 2008 Physical Activity Guidelines for Americans. The study showed that there is an inverse dose-response relationship between exercise intensity and coronary heart disease risk reduction. That is, though engaging in moderate exercise such as brisk walking reduces risk, more intense exercise is associated with greater risk reduction.

In addition to improving cardiac patients' quality of life, improved fitness helps older adults to live independent lives (Leon et al., 2005). Engaging in exercise training and activities such as stairs climbing, walking, doing household chores, cycling, etc. are necessary to improve cardiac patients' physical fitness (AHA, 2005).

Intensity of physical activity prescribed to older adults should be dependent on the physical fitness and the ability of the individual. Low to moderate intensity regular physical 
activity is good place to start to help to maintain or improve sedentary older adults functional fitness; where as those who are already active would need more intense physical activity to see greater results. After reviewing several articles, the authors concluded that there is a divided view on the volume and capacity as well as the kind of physical activity that is needed to improve the general fitness of older adults (Heath \& Stuart, 2002).

The findings of the current study that only $17.6 \%$ (22 of 125) participants met the ACSM's recommendation indicate that older adults in this sample do not engage in enough physical activity to impact their health. With regards to the functional fitness classification, the findings suggest that even though nearly $1 / 2$ of the participants were generally classified as normal, $1 / 4$ were classified as below normal indicating that they are at risk of a reduction in their functional fitness. It is also interesting that $1 / 4$ of participants were classified as above normal on their functional fitness measures, even though they did not meet physical activity recommendations suggested by the ACSM. Sixty six percent of the participants BMI was classified as above normal which may have resulted from and/or contributed to their inability to meet the ACSM's recommendations and successfully perform the activities in the senior fitness test.

The main finding of this study was related to time spent in MVPA and how this was related to functional fitness. Pearson correlation coefficient revealed a statistically strong positive relationship between the 5 day MVPA and the 6 min walk $(\mathrm{F}=16.72, \mathrm{p} \leq 0.001)$, suggesting that greater time spent in moderate intensity physical activity is related to better aerobic endurance. Greater aerobic endurance is related the older adults' ability to walk greater distances, stair climbing, shop, sightsee while on vacation, etc. (Rikli and Jones, 1999a). There were also statistically strong relationship between the 5 day MVPA and chair stands ( $F=14.06, p$ 
$\leq 0.001)$ indicating that greater time spent in MVPA is related to greater lower body strength in older adults. The lower body strength helps older adults to climb stairs, walk and get out of chair, tub or car as well as reduce their chance of falling (Rikli and Jones, 1990a). Additionally, the findings showed that statistically significant coefficient $(F=13.36, p \leq 0.001)$ between MVPA and up \& go indicating that 5 day MVPA is positively related to an older adults' agility/dynamic balance. According to Rikli and Jones (1990a), improved agility/dynamic helps with older adults' ability to perform quick maneuvers such as getting off a bus in a timely manner, going to the bathroom or answering the phone or to attend to something in the kitchen.

Consistent with the Pearson's coefficient correlation, ANOVAs revealed a cut-off point with regard to time spent in MVPA on the functional fitness measures the 6 min walk, chair

stands, and up \& go, and arm curls. For lower body function, the results suggest that 20 minutes of MVPA, 5 day per week is may be enough to positively impact functional fitness and that additional time in MVPA may not result in significantly greater performance on these measures. A threshold of 20 minutes may suggest that engaging in more than 20 min MVPA will not yield additional statistical gain on the mobility and lower body strength measures of 6 minute walk, chair stand, and up-and-go. For upper body strength and flexibility, the results suggest that less than 10 minutes of MVPA is detrimental to performance. However, additional time spent in MVPA did not result in greater gains in upper body strength.

\subsection{Conclusion}

ACSM recommends that to maintain health all adults accumulate at least 30 minutes of MVPA 5 days/wk. However, this study was designed to begin the investigation regarding the lowest dose possible to maintain functional fitness. Our data suggest that a threshold of 20 
minutes of MVPA may be enough to impact older women's lower body functional fitness and additional time spent in MVPA may not result in significant improvements in lower body functional fitness. For older women to benefit from regular physical activity and maintain their upper body strength, our findings show that they need to engage in >10 min of MVPA.

\subsection{Future Studies}

The results of this study suggest 20 minutes of MVPA 5 days a week is enough to impact lower body functional fitness. However the ACSM also recommends flexibility, strength, and balance exercises. Future studies should incorporate flexibility, strength, and balance exercises to determine a cut-off or dose response of these exercises with respect to their impact on functional fitness. 
BIBLIOGRAPHY 


\section{BIBLIOGRAPHY}

Abbott, R. D., White, L. R., Ross, G. W., Masaki, K. H. Curb, J. D. and Petrovitch, H. (2004). Walking and dementia in physically capable elderly Men. JAMA, 292:1447-1453.

Ainsworth B. E., Haskell, W. L., Leon, A. S., et al. (1993). Compendium of physical activities: classification of energy costs of human physical activities. Med Sci Sports Exerc, 25:71- 80.

American College of Sports Medicine. (1998). Exercise and physical activity for older adults. MSSE, 30:992-1008.

American College of Sports Medicine. (1998a). The recommended quantity and quality of exercise for developing and maintaining cardiorespiratory and muscular fitness, and flexibility in healthy adults. Med. Sci. Sports. Exerc. 30:975-991.

Aoyagi, Y., Park, H., Watanabe, E., Park, S., \& Shephard, R. J. (2009). Habitual physical activity and physical fitness in older Japanese adults: The Nakanojo study. Gerontology, 523531.

Brach, J. S., Simonsick, E. M., Kritchevsky, S., Yaffe, K., \& Newman, A. B. (2004). The association between physical functioning and lifestyle activity and exercise in the health, aging and body composition study. American Geriatrics Society, 502-509.

Bravata, D., Smith-Spangler, C., Sundaram, V., Gienger, A., Lin, N., Lewis R., et al. (2007). Using pedometers to increase physical activity and improve health: a systematic review. The Journal of the American Medical Association, 2296-2304.

Borg, G. A. (1982). Psychophysical bases of perceived exertion. Med. Sci. Sports. Exerc. 14:377381.

Buchman, A. S., Boyle, P. A., Yu, L., Shah, R. C., Wilson, R. S., et al. (2012). Total daily physical activity and the risk of AD and cognitive decline in older adults. Neurology, 78:13231329.

Campell, A. J, Robertson, M. C, Gardner, M. M, Norton, R. N, Tilyard, M. W, Buchner, D. M. (1997). Randomised controlled trial of a general practice programme of home based exercise to pr event falls in elderly women. BMJ, 315(7115):10659.

Christensen, H, Korten, A, Jorm, A. F, Henderson, A. S, Scott, R, and Mackinnon, A. J. (1996). Activity levels and cognitive functioning in an elderly community sample. Age Ageing. 25:7280 . 


\section{BIBLIOGRAPHY (Continued)}

Caspersen, C. J., Powell, K. E., and Christenson, G. M. (1985). Pysical activity, exercise, and physical fitness: Definitions and distinctions for health-related research. Public Health Reports. 100(4): 126-131.

Crouter, S. E., Schneider, P. L., Karabulut, M., Bassett, D.R. Jr. (2003). Validity of 10 electronic pedometers for measuring steps, distance, and energy cost. Med Sci Sports Exerc., 35;1455-60.

Doherty, T. J. Invited review: Aging and sarcopenia. J. Appl. Physiol. 954:1717-1727.

Donato, A. J., K. Tench, D. H., Glueck, D. R., Seals, I., Eskurza, and H. Tanaka H. (2003).

Declines in physiological functional capacity with age: a longitudinal study in peak swimming performance. J. Appl. Physiol. 94:764-769.

DiPietro, L. (2001). Physical activity in aging: changes in patterns and their relation to health and function. J. Gerontol. A Biol. Sci. Med. Sci. 56:13-22.

Dishman, R. K, Washburn, R. A, Heath, G. W. (2004). Physical Activity Epidemiology, 1st edition, Human Kinetics.

Drewnowski, A., and W. J. Evans, W. J. (2001). Nutrition, physical activity, and quality of life in older adults: summary. J. Gerontol. A Biol. Sci. Med. Sci. 56A:89-94.

Emery, C. F, Schein, R. L, Hauck, E. R, and MacIntyre, N. R. (1998). Psychological and cognitive outcomes of a randomized trial of exercise among patients with chronic obstructive pulmonary disease. Health Psychol. 1998;17:232-240.

Ferucci, L., Penninx, B. W., Leveille, S. G., Corti, M. C, Pahor, M., Wallace, R. et al. (2000). Characteristics of nondisabled older persons who perform poorly in objective tests of lower extremity function. (2000). J Am Geriatr Soc., 48(9):110210.

Franco, O. H., de Laet, C., Peeters, A., Jonker, J., Mackenbach, J., et al. (2005). Effects of physical activity on life expectancy with cardiovascular disease. Arch Interm Med., 165:23552365.

Fiatarone-Singh, M. A., (2001). Exercise for disease prevention in the geriatric population. Nutrition in Clinical Care, 4, 296-305.

Haskell, Lee, Pate, Powell, Blair, et al. (2007). Physical activity and public health: Updated recommendation for adults from the American College of Sports Medicine and the American Heart Association. Med. Sci. Sports Exerc., 39:8;1423-1434. 
BIBLIOGRAPHY (Continued)

Haskell, W. L. (1994). Health consequences of physical activity: Understanding and challenges regarding dose-response. Medicine and Science in Sports and Exercise; 226, 649-660.

Heath, J. M., and Stuart, M. R. (2002). Prescribing exercise for frail elders. JABFP; 15:218-28.

Hunter, G. R., Wetzstein, C. J., McLafferty Jr. C. R., Zuckerman, P. A., Landers, K. A. and Bamman, M. M. (2001). High-resistance versus variable-resistance training in older adults. Med. Sci. Sports Exerc. 33:1759-1764.

Kovar, P. A., Allegrante, J. P., MacKenzie, C. R., Peterson, M. G., Gutin, B., and Charlson, M. E. (1992) Supervised fitness walking in patients with osteoarthritis of the knee. A randomized controlled trial. Ann Intern Med., 116(7):52934.

Leon, A. S., Franklin, B. A., Casta, F., Balady, G. J., Berra, K. A., et al. (2005). Cardiac rehabilitation and secondary prevention of coronary heart disease: An American Heart Association Scientific Statement. Circulation. 2005; 111: 369-376.

Miotto, J. M., Chodzko-Zajko, W. J., Reich, J. L., and Supler, M. M. (1999). Reliability and validity of the Fullerton Functional Fitness Test: an independent replication study. J. Aging Phys. Activ. 7:339-353.

Morgan, A. L., Rogers, N. L., Takeshima, N., Amini, S., \& Ofei-Dodoo, S. (2011). Impact of moderate intensity physical activity on the functional fitness of older women. Journal of American College of Sport Medicine.

Morgan, A. L., Tabor, D. A., \& Snyder, L., (2010). Walking toward a new me: The impact of prescribed walking 10,000 steps/day on physical and psychological well-being. Journal of Physical Activity and Health, 2010; 7: 299-307.

Moreland, J., Richardson, J., Chan, D. H., O'Neill, J., Bellissimo, A., Grum, R. M., and Shanks, L. (2003). Evidence-based guidelines for the secondary prevention of falls in older adults. Gerontology 49:93-116.

Nagasak, I. H., Itoh, H., \& Furuna, T. (1995). A physical fitness model of older adults. Aging Clinical and Experimental Research, 392-397.

Nelson, M. E., Rejeski, W. J., Blair, S. N., Duncan, P. W., Judge, J. O., King, A. C., et al. (2007). Physical activity and public health in older adults: recommendation from the American College of Sports Medicine and the American Heart Association. Medicine and Science in Sport and Exercise, 1435-1445.

Purath, J., W., Buchholz, S., \& L.Kark, D. (2009). Physical fitness assessment of older adults in the primary care setting. Journal of the American Academy of Nurse Practitioners, 101 - 107. 


\section{BIBLIOGRAPHY (Continued)}

Rennie, K. L., Hemingway, H., Kumari, M., Malik, M., and Marmot, M. (2003). Effects of moderate and vigorous physical activity on heart rate variability in British Study of civil servants. Am J Epidemiol, 158:135-143.

Rikli, R., \& Jones, C. J., (1999a). Development and validation of a functional fitness test for community-residing older adults. J. Aging Phys. 7:129-161.

Rogers, M. E., Sherwood, H. S., Rogers, N. L and Bohlken, R. M. (2002). Effects of dumbbell and elastic band training on physical function in older inner-city African American women. Women \& Health 36:4, 33-41.

Rogers, M. A, and W. J. Evans, W. J. (1993). Changes in skeletal muscle with aging: effects of exercise training. Exerc. Sports Sci. Rev. 21:65-102.

Rogers, M. E., Rogers, N. L., Takeshima, N., and Islam, M. M. (2003). Methods to evaluate and improve the physical parameters associated with fall risk in older adults. Prev. Med. 36:255-264.

Rowe, D. A., Kemble, C. D., \& Robinson, T. S. (2007). Daily walking in older adults: day-today variability and criterion-referenced validity of total daily step counts. Journal of Physical Activity and Health, 434-446.

Simpson, M. E., Serdula, M., Galuska D. A., et al. (2003). Walking trends among U.S. adults: the Behavioral Risk Factor Surveillance System, 1987-2000. Am J Prev Med, 25:95-100.

Takeshima, N., Tanaka, K., Kobayashi, F., Sumi, K., Watanabe, T., and Kato, T. (1993).Effects of aerobic exercise conditioning at intensities corresponding to lactate threshold in the elderly. Eur. J. Appl. Physiol. 67:138-143.

Task force of the European Society of Cardiology and the North American of Pacing and Electrophysiology. Heart rate variability: standards of measurement, physiological interpretation and clinical use. Circulation1996; 93:1043-65.

Taylor, H. L, Jacobs, D. R. Jr., Schucker B, et al. (1978). A questionnaire for the assessment of leisure time physical activities. J Chronic Dis, 31:741-55.

Tanasescu, M., Leitzmann, M. F., Rimm, E. B., Willett, W. C., Stampfer, M. J., and Hu, F. B. (2002). Exercise type and intensity in relation to coronary heart disease in men. JAMA, 288: 1994-2000.

Toraman, N. F., Erman, A., and Agyar, E. (2004). Effects of multicomponent training on functional fitness in older adults. J. Aging Phys. Activ. 12:538-553. 


\section{BIBLIOGRAPHY (Continued)}

Tudor-Locke, C., \& Bassett Jr., D. (2004). How many steps/day are enough? Preliminary pedometer indices for public health. Sports Medicine, 1-8.

Tudor-Locke, C., Hart, T. L., \& Washington, T. L. (2009). Expected values for pedometerdetermined physical activity in older population . International Journal of Behavioral Nutrition and Physical Activity.

U.S. Department of Health and Human Services. 2008 Physical Activity Guidelines for Americans. 2008.

U.S. Department of Health and Human Services. Promoting active lifestyles among older adults. 2001.

United Nations. (2003). World population prospects: The 2002 revision. United Nations Population Division.

Voloshin, A. (1988). Shock absorption during running and walking. J. Am. Podiatr. Med. Assoc. 78:295-299.

Williams, D. M., Matthews, C., Rutt, C., Napolitano, M. A., \& Marcus, B. H. (2008). Interventions to increase walking behavior. Med Sci Sports Exerc., 40(7 Suppl): S567- S573.

Woolf, K., Reese, C., Mason, M., Beaird, L., Tudor-Locke, C., \& Vaughan, L. (2009). Physical activity is associated with risk factors for chronic disease across adult women's life. Journal of the American Dietetic Association, 248-259.

Yaffe, K., Barnes D., Nevitt M., Lui L., and Covinsky K. (2001). A prospective study of physical activity and cognitive decline in elderly women. Arch Intern Med. 161:1703-1708.

Yamauchi, T., Islam, M. M., Koizumi D., Rogers, M. E., Rogers, N. L., \& Takeshima, N. (2005). Effect of home-based well-rounded exercise in community-dwelling older adults. Journal of Sport Science and Medicine, 4, 563- 571. 
APPENDICES 


\section{APPENDIX A}

\section{CONSENT FORM}

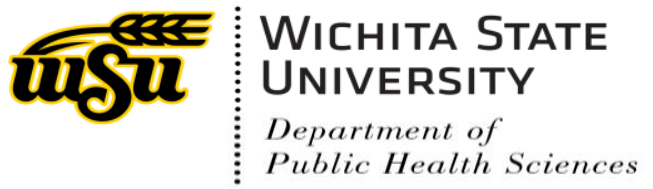

\section{Accelerometery-Determined Physical Activity and Functional Fitness in Older Adults}

You are invited to participate in a study to examine physical fitness and activity levels. We hope to identify relationships between daily physical activity and strength, balance, flexibility, mobility, and cardiovascular fitness in older individuals. Knowledge gained from this project will also assist exercise and medical professionals in prescribing activity and in helping older individuals maintain their independence. We would like you to take part in this study. You were selected as a possible participant in this study because your age is within the range in which we are interested. We will recruit approximately 300 people to participate in this project. If you decide to participate, you will be asked to perform a series of assessments. These assessments are designed to measure your ability to maintain your balance and to measure your functional ability. The assessments will be done at the site you were recruited from.

During the assessments we will ask you to stand on a balance platform and on a piece of foam while your balance is assessed. You will also perform a timed test where you will be asked to stand from a chair, walk 8 feet, and return to the chair. Your lower body flexibility will be assessed while sitting in a chair and reaching toward your toes and strength will be assessed while rising from a chair and sitting down for 30 seconds. Your walking ability will be assessed by having you walk around a 50-yard perimeter for twelve minutes. Your upper body strength will be assessed while lifting a dumbbell ( 5 pounds for women, 8 pounds for men) for 30 seconds and flexibility by placing your arms behind your back. To measure your typical daily activity, you will be given a "locked" accelerometer, a small device attached at your waist, to wear for 2 weeks. We will explain when and where to wear the accelerometer. Two weeks after the assessments, we will meet with you at your recruitment site to "unlock" your accelerometer and record step counts for that week.

\section{$\underline{\text { Potential Risk }}$}

Physical movement rarely causes problems in healthy adults. However, if they suffer from hidden heart disease, an exercise test could cause chest pain, dizziness, or bouts of irregular heart rhythms. Also, there is always a slight risk of a heart attack occurring during the exercise tests in persons with preexisting heart disease. You will be asked about any type of disease that you may have. 
APPENDIX A (continued)

Muscle soreness could also occur following any of these physical activities. You will receive proper instruction for all activities. The supervisors of the program have extensive experience leading activities like the ones you will perform.

\section{Potential Benefits}

Many studies have found that poor functional fitness is a major limitation in gaining and maintaining physical independence. You will gain an understanding of your own physical abilities and an appreciation for the effects of physical activity on these parameters. In general, this study will improve the knowledge concerning the potential for improved functional fitness in older individuals, enhancing the ability to help people live independently for longer periods of time.

If you take part, your results will be combined with other participants so it will not be possible to identify your responses in a published report; your name will not be directly associated with any of the results.

You have been informed and you understand that Wichita State University does not provide medical treatment or other forms of reimbursement to persons injured as a result of or in connection with participation in research activities conducted by Wichita State University or its faculty. In an event where you believe that you have been injured as a result of participating in the research covered by this consent form, you should contact the Office of Research Administration, Wichita State University at 316-978-3285.

If you have any questions concerning this study, you may contact Dr. Rogers at work (316-9786684). You may also contact the Office of Research Administration at 316-978-3285.

YOU ARE MAKING A DECISION WHETHER OR NOT YOU WILL PARTICIPATE IN THIS STUDY. YOU SHOULD NOT SIGN UNTIL YOU UNDERSTAND ALL THE INFORMATION PRESENTED IN THE PREVIOUS PAGES AND UNTIL ALL YOUR QUESTIONS ABOUT THE RESEARCH HAVE BEEN ANSWERED TO YOUR SATISFACTION. YOUR SIGNATURE INDICATES THAT YOU HAVE DECIDED TO PARTICIPATE IN THIS STUDY. 


\section{APPENDIX A (continued)}

\section{You will be offered a copy of this letter to keep.}

I agree to take part in this project. I know what I will have to do and that I can stop at any time.

Signature of Participant

Date

Name Printed

Nicole L. Rogers, $\mathrm{PhD}$

Date

Principal Investigator 
APPENDIX B

EXERCISE AND SCREENING FOR YOU FORM

๖̊․․
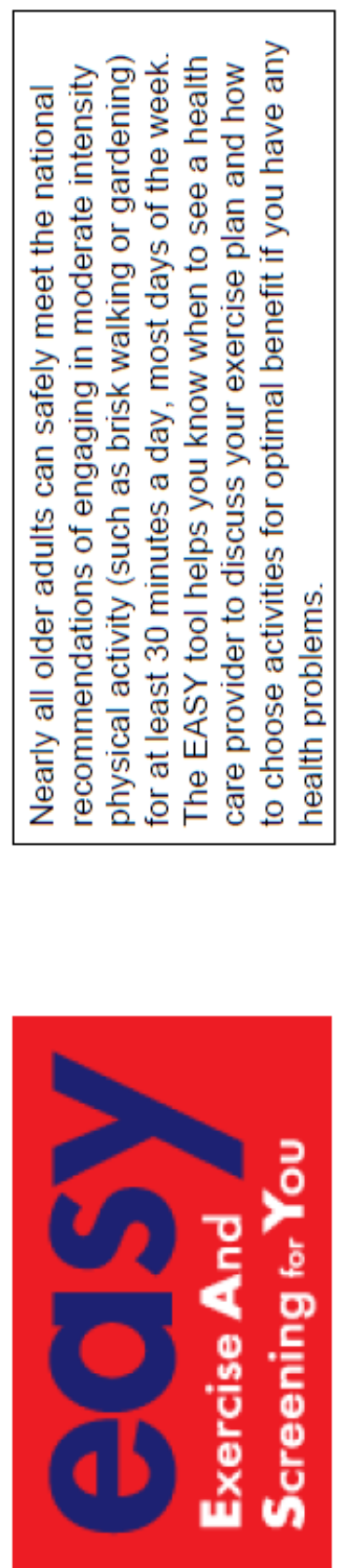
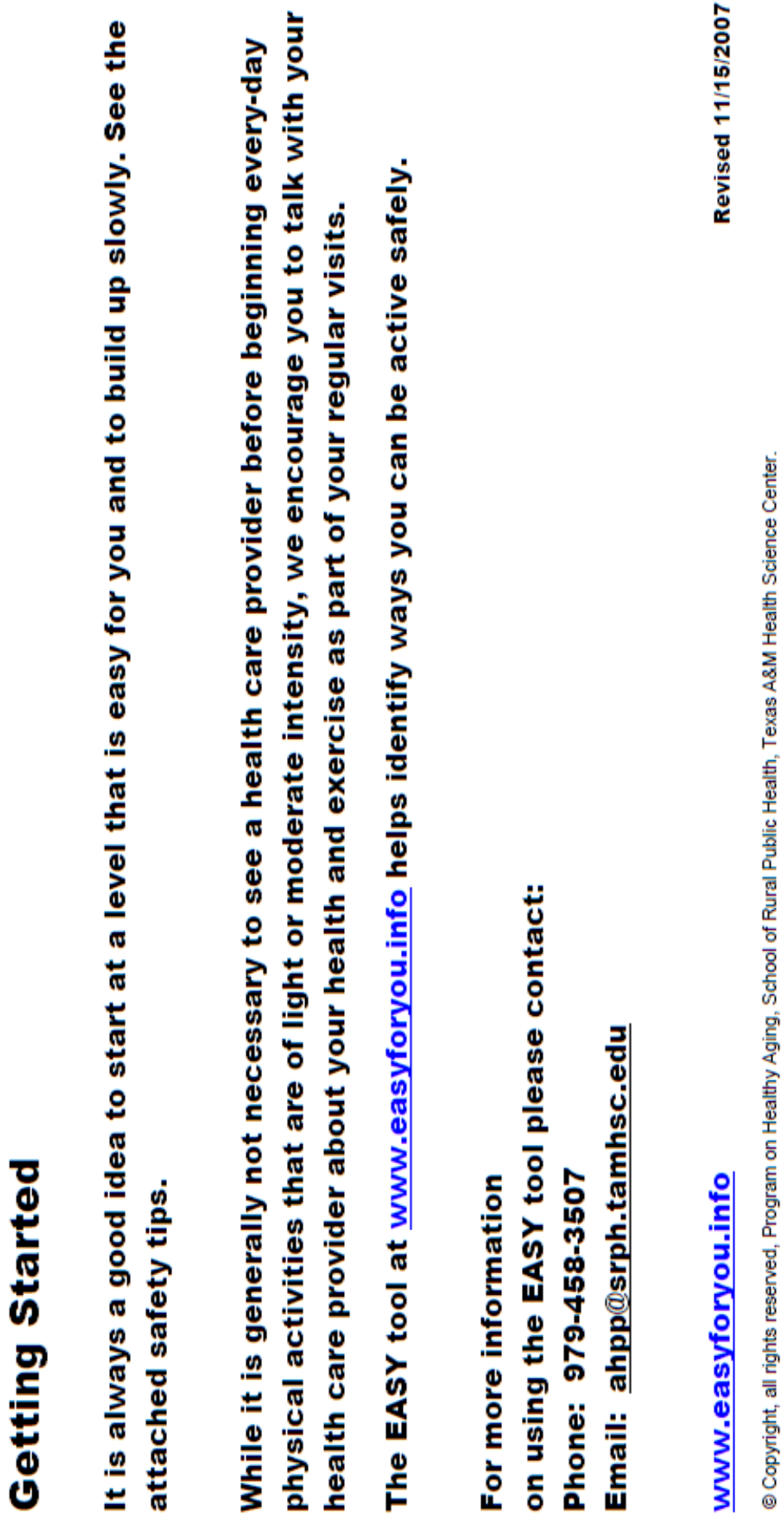


\section{APPENDIX C}

MEDICAL CLEARANCE FORM

\section{A Community-Based Multi-Component Physical Activity Program for Older Adults}

\section{MEDICAL CLEARANCE OF PERSONAL PHYSICIAN}

Your patient, , has expressed an interest in participating in a CommunityBased Walking Program, offered through the Department of Public Health Sciences Aging Studies Program and Department of Human Performance Studies at Wichita State University and Health Strategies.

We would appreciate your medical opinion and recommendations concerning this individual's participation in exercise. If you feel that this individual might benefit from participation in the program, we would greatly appreciate your endorsement of his/her participation.

Assessments: The program participants are asked to complete a series of functional fitness assessments as well as a moderate intensity walk. This are completed to identify weaknesses in physical parameters associated with activities of daily living and to more effectively prescribe appropriate exercise.

\begin{tabular}{|c|c|c|c|}
\hline Physical Parameters & Assessments & Approv & \\
\hline Cardiovascular & 12 minute walk & yes ___ & no___ \\
\hline \multirow[t]{5}{*}{ Muscular Strength / Endurance } & 30 second chair stand & yes & no \\
\hline & 30 second arm curl & yes___ & no \\
\hline & Flexibility & \multicolumn{2}{|c|}{ Chair sit-and-reach } \\
\hline & yes___ & no___ & \\
\hline & Back scratch & yes___ & no \\
\hline \multirow[t]{3}{*}{ Balance \& Gait } & 8 foot up-and-go & yes_ & no \\
\hline & Computerized Postural Sway & yes___ & no \\
\hline & Computerized Limits of Stability & yes___ & no \\
\hline Moderate Intensity Walk & $\begin{array}{l}15 \text { minute walk at moderate intensity } \\
\text { *wearing heart rate monitor }\end{array}$ & yes___ & no___ \\
\hline Submaximal exercise test & YMCA Bicycle Test & yes__ & no \\
\hline
\end{tabular}


APPENDICE C (continued)

Please list any modifications/comments for testing and the walking program:

Please indicate by your signature below that your patient is medically cleared to participate in the specific portions of testing and training as described. Please call Dr. Rogers if you have any question concerning the program at (316) 978-6684.

Signature of Physician Print Name of Physician Date

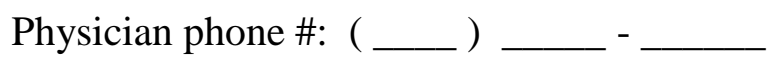

Please return this form by FAX or Postal Mail to:

Nicole L. Rogers, PhD

Fax: 316.978.3072

Assistant Professor, Aging Studies

Program Director, Aging Studies

Department of Public Health Sciences

College of Health Professions

Wichita State University

1845 Fairmount - Campus Box 43

Wichita, Kansas 67260

Phone: 316.978 .6684

Email: nicole.rogers@wichita.edu 
Participant ID

\section{APPENDIX D}

\section{Demographic Questionnaire}

1. What is your age in years?

_ years

2. What is your ethnic background?

$\square \quad$ White/Caucasian

$\square \quad$ Black/African American

$\square \quad$ Hispanic or Latino

$\square$ American Indian/Alaska Native/Pacific Islander

$\square \quad$ Asian or Asian/American

3. What is your marital status?

$\begin{array}{ll}\square & \text { Married/Or Live With Significant Other } \\ \square & \text { Single/Live By Self } \\ \square & \text { Divorced/widowed/live by self }\end{array}$

4. What is the highest grade you have completed in school? (record grade number)

5. What is the title of your current job/position? 


\section{APPENDIX D (Continued)}

6. List the "prescription" medications that you currently take: (by exact name or by type)

Type of medication

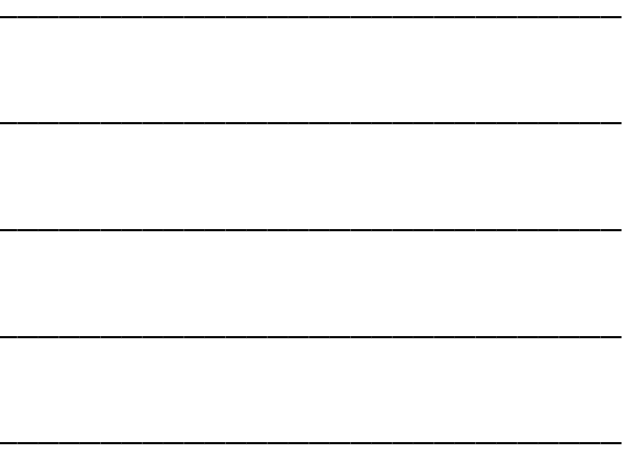

For what condition

\section{Smoking Status}

Do you currently smoke cigarettes? No ___ Yes

If yes, number of cigarettes smoked on an average day

If no, have you ever smoked?

No

Yes

For how many years?

How many cigarettes did you smoke on an average day

How many years since you stopped?

8. How many drinks of an alcoholic beverage do you have in a typical week?

Bottles or cans of beer

Glasses of wine

Wine coolers or other malt beverages

Mixed drinks or shots of liquor 